\title{
ATP-DEPENDENT POTASSIUM CHANNEL BLOCKADE STRENGTHENS MICROGLIAL NEUROPROTECTION AFTER HYPOXIA-ISCHEMIA IN RATS
}

Ortega $\mathrm{FJ}^{1}$, Gimeno-Bayon $\mathrm{J}^{1}$, Espinosa-Parrilla $\mathrm{JF}^{1}$, Carrasco $\mathrm{JL}^{3}$, Batlle $\mathrm{M}^{1}$, Pugliese $\mathrm{M}^{1,2}$, Mahy $\mathrm{N}^{1}$, *Rodríguez $\mathrm{MJ}^{1}$

1- Unitat de Bioquímica i Biologia Molecular, Facultat de Medicina, Institut d'Investigacions Biomèdiques August Pi i Sunyer (IDIBAPS), Universitat de Barcelona and Centro de Investigación Biomédica en Red sobre Enfermedades Neurodegenerativas (CIBERNED), Barcelona, Spain.

2- Neurotec Pharma SL, Bioincubadora del Parc Científic de Barcelona, Barcelona, Spain

3- Unitat de Bioestadística, Departament de Salut Pública, Facultat de Medicina, Universitat de Barcelona, Barcelona, Spain

Author for correspondence: Dr. Manuel J. Rodríguez

Unitat de Bioquímica i Biologia Molecular

Facultat de Medicina, UB

c/ Casanova 143

E-08036 Barcelona, SPAIN

Phone: +34934020586

FAX: + 34934035882

e-mail: marodriguez@ub.edu 


\section{ABSTRACT}

Stroke causes CNS injury associated with strong fast microglial activation as part of the inflammatory response. In rat models of stroke, sulphonylurea receptor blockade with glibenclamide reduced cerebral edema and infarct volume. We postulated that glibenclamide administered during the early stages of stroke might foster neuroprotective microglial activity through ATP-sensitive potassium $\left(\mathrm{K}_{\mathrm{ATP}}\right)$ channel blockade. We found in vitro that $\mathrm{BV} 2$ cell line showed upregulated expression of $\mathrm{K}_{\mathrm{ATP}}$ channel subunits in response to pro-inflammatory signals and that glibenclamide increases the reactive morphology of microglia, phagocytic capacity and TNF $\alpha$ release. Moreover, glibenclamide administered to rats 6,12 and 24 hours after transient Middle Cerebral Artery occlusion improved neurological outcome and preserved neurons in the lesioned core three days after reperfusion. Immunohistochemistry with specific markers to neuron, astroglia, microglia and lymphocytes showed that resident amoeboid microglia are the main cell population in that necrotic zone. These reactive microglial cells express SUR1, SUR2B and Kir6.2 proteins that assemble in functional $\mathrm{K}_{\mathrm{ATP}}$ channels. These findings provide evidence for the key role of $\mathrm{K}_{\mathrm{ATP}}$ channels in the control of microglial reactivity are consistent with a microglial effect of Glibenclamide into the ischemic brain and suggest a neuroprotective role of microglia in the early stages of stroke. 


\section{INTRODUCTION}

ATP-sensitive potassium $\left(\mathrm{K}_{\mathrm{ATP}}\right)$ channels are expressed by neurons of different brain regions (Ashford, et al., 1990, Levin, 2001, Ohno-Shosaku and Yamamoto, 1992) and other cell types such as pancreatic $\beta$-cells (Aguilar-Bryan, et al., 1995, Ashcroft, et al., 1987), in which they act as energy sensors of ATP production. The expression of $\mathrm{K}_{\mathrm{ATP}}$ channels has also been suggested in microglia (McLarnon, et al., 2001, RAMONET2004, Ramonet, et al., 2004). $\mathrm{K}_{\mathrm{ATP}}$ channels are assembled as a hetero-octameric complex (Clement, et al., 1997, Mikhailov, et al., 2005, Proks and Ashcroft, 2009, Wheeler, et al., 2008) from two structurally distinct subunits: the regulatory sulphonylurea receptor (SUR), a member of the ATP-binding cassette protein family with 3 isoforms SUR1, SUR2A and SUR2B, and the pore forming inwardly rectifying $\mathrm{K}^{+}$channel (Kir) subunit 6.1 or 6.2 . Sulphonylureas such as glibenclamide (Gbc) close the channel by interaction with two drug-binding sites on SUR subunits (Mikhailov, et al., 2001) and are used to treat diabetes.

In several rat models of stroke, blockade of SUR with low doses of Gbc reduced cerebral edema and infarct volume, and decreased mortality by 50\% (Simard, et al., 2010). These cytoprotective effects of $\mathrm{Gbc}$ are related to the astroglial $\mathrm{NC}_{\mathrm{Ca}-\mathrm{ATP}}$ channel, whose activity is under SUR1 control (Chen, et al., 2003). However, as SUR assembles with Kir6.x subunits to constitute functional $\mathrm{K}_{\mathrm{ATP}}$ channels, other possible effects of Gbc might explain the effectiveness of this drug in the treatment of stroke.

Microglia generally considered the immune cells of the CNS (Graeber and Streit, 2010, Kim and de Vellis, 2005, Napoli and Neumann, 2009), normally monitories brain environment and synapse functional status (Wake, et al., 2009). After injury, microglia adopt an amoeboid shape, show an upregulated variety of surface molecules and release of cytokines. Excessive production of pro-inflammatory and neurotoxic factors from activated microglia, such as nitric oxide (NO), tumor necrosis factor a $(\mathrm{TNF} \alpha)$, interleukin- $1 \beta$ and reactive oxygen 
species, may trigger or exacerbate neuronal death (Acarin, et al., 2000). However considerable evidence after ischemia shows that microglia response caused by injured/dying neurons mediate a reduction of neuronal damage and induction of tissue repair (Kitamura, et al., 2004, Lalancette-Hébert, et al., 2007, Neumann, et al., 2006, Neumann, et al., 2008, Shaked, et al., 2005, Streit, 2002, Thored, et al., 2009). For example, experimental transient astroglial ablation in the hippocampus and other brain regions is associated with a protective microglial reaction that avoids any neuronal injury over several days (Rodriguez, et al., 2004). Consequently, in pathological processes microglia show a hybrid activation state that includes inflammatory actions and also characteristics of neuroprotection and repair (Hanisch and Kettenmann, 2007, Milligan and Watkins, 2009, Streit, 2005, Thored, et al., 2009). In any case, in response to neuronal damage fast activation of microglia requires the rapid availability of a large amount of energy to trigger diverse cytotoxic or neuroprotective signals. The expression of $\mathrm{K}_{\mathrm{ATP}}$ channels in activated microglia, coupling cell energy to membrane potential may then be critical in determining, at least in part, their participation in the pathogenic process.

If this is the case, Gbc effects in stroke should include strengthening of neuroprotective microglial activity. We studied the effects of Gbc on microglial inflammatory and phagocytic activities in cultures of the BV2 microglial cell line and then, investigated this possibility in the transient middle cerebral artery occlusion (tMCAo) rat stroke model, by a combined functional, imaging, histological and stereological approach. We then. We report that once activated, microglia upregulates the expression of $\mathrm{K}_{\mathrm{ATP}}$ channels and blockade of the channel by Gbc fosters the neuroprotective activity of microglia in the early stages of injury, which facilitates major improvements in stroke outcome. 


\section{MATERIAL AND METHODS}

\section{Animals}

Adult male Wistar rats (3 months old, body weight 250-300 $\mathrm{g}$ at the beginning of the study) were obtained from Charles River Laboratories (Sulzfeld, Germany). They were kept on a 12 hours/12 hours day and night cycle and housed with free access to food and water. Animals were handled according to European legislation (86/609/EEC). All efforts were made to minimize the number of animals used and their suffering. Experiments were conducted according to the National Institutes of Health $(\mathrm{NIH})$ guidelines for the care and use of laboratory animals. Procedures were approved by the Ethics Committee of the Universitat de Barcelona, in accordance with the regulations established by the Catalan government (Generalitat de Catalunya).

\section{Materials}

Cell line of murine BV2 microglia was purchased from Cell Bank (Interlab Cell Line Collection, ICLC, Geneva, Italy). Gbc, Isolectine B4 Peroxidase-conjugated (IB4), mouse monoclonal anti-Glial fibrillary acidic protein (GFAP) antibody and mouse monoclonal antialpha-tubulin FITC conjugate were purchased from Sigma-Aldrich (St Louis, MO). Goat polyclonal anti-SUR1 (C-16), goat polyclonal anti-SUR2B (C-15) and mouse monoclonal anti-CD3 (PC3/188A) antibodies were from Santa Cruz Biotechnology (Santa Cruz, CA). Rabbit anti-Kir6.1 and mouse anti-Kir6.2 were from Alomone Labs (Jerusalem, Israel). Mouse monoclonal anti-neuronal $(\mathrm{NeuN})$ antibody was obtained from Chemicon (Temecula, CA). Mouse anti-rat CD11b (OX-42 clone) was purchased from Serotec (Oxford, UK) and rabbit anti-S100 $\beta$ antibody from Dako (Glostrup, Denmark). $\left[{ }^{3} \mathrm{H}\right]$ Glibenclamide (43.3 Ci/mmol) was supplied by Perkin Elmer (Waltham, MS). Primers for RT-PCR analysis were synthesized by Roche Diagnostics (TIB-MOLBIOL, Berlin, Germany). Other reagents and 
secondary antibodies were supplied from different sources, as described below.

\section{Culture, morphology study and immunocytochemistry of BV2 microglia}

BV2 cells were cultured in RPMI 1640 medium with L-glutamine and supplemented with $10 \%(\mathrm{v} / \mathrm{v})$ heat-inactivated fetal bovine serum (FBS), 100U/ml penicillin and $100 \mu \mathrm{g} / \mathrm{ml}$ streptomycin. Cells were grown in a humidifier cell incubator containing $5 \% \mathrm{CO}_{2}$ at $37^{\circ} \mathrm{C}$. Before activation, cells were sub-cultured on 24-well plates at a density of $5 \times 10^{4}$ cells $/ \mathrm{ml}$ for 24 hours and then activated with lipopolysaccharide (LPS) and interferon gamma (IFN $\gamma)(0.1$ $\mu \mathrm{g} / \mathrm{ml}$ and $0.05 \mathrm{ng} / \mathrm{ml}$ ), as described elsewhere (Saura, et al., 2003).

A Gbc working solution was prepared in DMSO and diluted 1:50 (v/v) in culture medium. Cell cultures were pre-treated 30 minutes before or post-treated 24 hours after activation with LPS+IFN $\gamma$ with either $1,10^{-3}$ or $10^{-5} \mathrm{nM}$ Gbc diluted in culture medium (DMSO final concentration $<0.01 \%$ ). A control group without activation but treated with $1 \mathrm{nM} \mathrm{Gbc}$ was added to each treatment-group. 48 hours after activation, culture media were collected for further analysis.

For immunocytochemistry assays, BV2 cells were grown on poly-D-lysine-coated sterile coverslips and the medium was changed on day of activation with LPS+IFN $\gamma$. At 48 hours, cells were fixed in ice-cold methanol for 30 seconds. Immunodetection used anti-SUR1 (1/100), anti-Kir6.1 or anti-Kir6.2 (1/400) primary antibodies detected with AlexaFluor-488 conjugated secondary antibodies (1/500). Controls for non-specific binding were performed excluding primary antibodies. Cell nuclei were stained with Hoescht33258 $(0.5 \mu \mathrm{g} / \mathrm{ml}$ in PBS). Coverslips were mounted with Pro-long Antifade and slices were stored at $4^{\circ} \mathrm{C}$.

For cell morphology analysis, direct immunofluorescence was carried out with anti-alphatubulin FITC conjugated as primary antibody (1/500), in which 5 random pictures/well were taken by a Leica DMI 6000B inverted microscope equipped with LAS AF Leica software 
(Leica Microsystems Heidelberg GmbH, Mannheim, Germany). In each picture, the area and perimeter of every individual cell were measured by ImageJ $1.39 \mathrm{u}$ (National Institutes of Health, USA).

To study their phagocytic capacity, cells were incubated for $2,5,15$ and 30 minutes at $37^{\circ} \mathrm{C}$ in the presence of $2 \mu \mathrm{m}$ diameter FluoSpheres at $0.01 \%$ solid mass, as described elsewhere (Saura, et al., 2003). In parallel, immunofluorescence with anti-alpha-tubulin antibody conjugated with FITC was employed for cell identification as described above. To analyze phagocytic capacity, 5 random pictures/well were taken and cells containing at least one fluosphere were counted in each picture. Results are given as a percentage of the total number of cells per well.

\section{RT-PCR and Western blotting of $K_{\mathrm{ATP}}$ channel components in BV2 cells}

RT-PCR was performed to assess the presence of SUR1, Kir6.1 and Kir 6.2 mRNA in BV2 cells. Total RNA from BV2 cells was isolated using NucleoSpin RNA/protein kit in line with the manufacturer's instructions (Macherey-Nagel, Germany). The concentration of total RNA isolated was quantified by a NanoDrop N1000 spectrophotometer (Thermo, Wilington, DE). Specific primers were designed against mouse mRNA sequences (Genbank Accession numbers in brackets) of Kir6.1 (NM_008428.4), Kir6.2 (NM_010602.2), SUR1 (NM_011510.3), SUR2A (D86037) and SUR2B (D86038) as described elsewhere (Morrissey, et al., 2005). Sequence of 18S non-coding mRNA (NR_003278.1) was used as control (Table 1). RT reactions were carried out using random primers and $2 \mu \mathrm{g}$ of mRNA with the AffinityScript Multiple Temperature cDNA Synthesis kit (Stratagene, CA). PCR was performed with the Taq PCR Core kit from Qiagen (Studio City, CA), using $2 \mu 1$ of RT reaction as a template. The cycling conditions for Kir6.1, Kir6.2 and SUR1 were those described elsewhere (Morrissey, et al., 2005). For 18S mRNA, cycling conditions had the 
annealing temperature fixed at $57^{\circ} \mathrm{C}$ in line with the manufacturer's instructions. Appropriate templates were included as positive and negative controls. PCR products $(10 \mu \mathrm{l})$ were separated by $1.5 \%$ agarose gel electrophoresis and viewed by staining with ethidium bromide. Whole-cell culture proteins were obtained in RIPA buffer (Santa Cruz Biotechnology, Santa Cruz, CA) and brain homogenates, as described elsewhere (Acarin, et al., 2000). The supernatant and the pellet were collected. Aliquots containing $15 \mu \mathrm{g}$ protein were subjected to $10 \%$ SDS-PAGE. Proteins were transferred to Nitrocellulose membrane (Amersham Pharmacia Biotech, San Francisco, CA) and probed by incubation with anti-SUR1 (1/100), anti-Kir6.1 and anti-Kir6.2 (1/500) as primary antibodies and with peroxidase-conjugated IgG as secondary antibody (1/2500; Sigma-Aldrich, St Louis, MO). Blots were viewed by the enhanced chemiluminescence system ECL-Plus, according to the manufacturer's instructions, and exposed to X-ray film (Amersham Pharmacia Biotech, San Francisco, CA).

\section{Quantification of NO and TNF $\alpha$ production by BV2 cells}

NO production was assessed in culture supernatants by the Griess reaction, a colorimetric assay that detects nitrite $\left(\mathrm{NO}^{2-}\right)$ as a stable reaction product of $\mathrm{NO}$ with molecular oxygen (Green, et al., 1982). Briefly, $50 \mu \mathrm{L}$ of each sample was incubated with $25 \mu \mathrm{L}$ of Griess reagent A ( $1 \%$ sulfanilamide, $5 \%$ phosphoric acid) and $25 \mu \mathrm{L}$ of Griess reagent $\mathrm{B}(0.1 \% \mathrm{~N}-1$ naphthylenediamine) for $5 \mathrm{~min}$. The optical density of the samples was measured at $540 \mathrm{~nm}$ by a microplate reader (Sunrise-Basic Reader, TECAN). The nitrite concentration was determined from a sodium nitrite standard curve. The amount of TNF $\alpha$ released in the cell culture supernatants was determined by an ELISA murine TNF $\alpha$ kit (PeproTech; London, UK), following the manufacturer's guidelines.

\section{tMCAo surgery and drug delivery}


Focal ischemia was produced by tMCAo using the intraluminal filament technique (Van Groen, et al., 2005). Rats were anesthetized by 5\% halothane (in $70 \% \mathrm{~N}_{2} \mathrm{O} / 30 \% \mathrm{O}_{2}$ ). A surgical depth of anesthesia was maintained throughout the operation with 0,5 to $1 \%$ halothane, delivered though a nose mask. To occlude blood flow to the right MCA territory, a heparinized nylon monofilament $(0.25 \mathrm{~mm}$ diameter, tip blunted) was advanced $21-23 \mathrm{~mm}$ into the internal common carotid artery until resistance was felt. The filament was held in place by tightening a suture around the internal common carotid artery and placing a microvascular clip around the artery. After $60 \mathrm{~min}$ of occlusion, the MCA blood flow was restored by removal of the filament, and the external carotid artery was permanently closed by electrocoagulation. For the assessment of Gbc bioavailability, permanent MCAo was performed following the same procedure but without the filament being removed. In all cases, body temperature was monitorized and maintained above $36.5^{\circ} \mathrm{C}$ with a homoeothermic blanket system. Successful tMCAo was verified by assessing sensory motor impairment and by measuring infarct volumes at the end of the study. To prevent dehydration, all animals received a daily i.p. injection of saline ( $4 \mathrm{ml}$ per rat). Animals showing 0-lesion (no detectable infarct) or hemorrhagic transformations (visual inspection) were excluded from the study.

\section{Calculation of Glibenclamide bioavailability}

To calculate whether Gbc can reach the brain of MCAo rats, 3 animals received an i.p. injection of $100 \mu \mathrm{Ci}\left[{ }^{3} \mathrm{H}\right]$ Glibenclamide in a volume of $0.9 \mathrm{ml} / \mathrm{rat}, 16$ hours after permanent MCAo, This model was used because the permanent occlusion of the artery avoids blood entering into the ischemic brain. Two hours later, they were anesthetized with isofluorane and transcardially perfused with $200 \mathrm{ml}$ of $0.1 \mathrm{M}$ phosphate buffer saline (PBS, pH 7.4). Brains were quickly removed (the right and left hemispheres collected separately), frozen in liquid $\mathrm{N}_{2}$ and stored. Tissue samples were manually homogenized in 7 volumes of ice-cold $50 \mathrm{mM}$ 
Tris- $\mathrm{HCl}(\mathrm{pH}$ 7.6) and radioactivity was counted in triplicate. $100 \mathrm{ml}$ homogenate was diluted in $10 \mathrm{ml}$ scintillation cocktail and mixed for 2 hours. Specific ${ }^{3} \mathrm{H}$ emission was counted in each solution for 60 seconds using a LS3801 Liquid Scintillation Counter (30\% efficiency). Two blank samples (non-radioactive tissue homogenate and distilled water) were also included in the study. The Bradford method was used to calculate the protein content of each sample (Bradford, 1976).

\section{Dose-response, functional evaluation and imaging studies}

To evaluate the effects of Gbc on tMCAo by means of functional, histological and immunohistochemical studies, 60 animals were divided into four groups ( $\mathrm{n}=15$ /group). Each rat received three $0.2 \mathrm{ml}$ injections of either $0.01 \mathrm{M} \mathrm{PBS}(\mathrm{pH} 7.4), 0.02 \mu \mathrm{g}, 0.2 \mu \mathrm{g}$, or $2 \mu \mathrm{g}$ Gbc into the tail vein (in total, then, the three Gbc doses where $0.06 \mu \mathrm{g}, 0.6 \mu \mathrm{g}$ and $6 \mu \mathrm{g}$ ). Injections were given at 6,12 and $24 \mathrm{~h}$ after reperfusion. Gbc was prepared in DMSO and diluted in $0.01 \mathrm{M}$ PBS to the final concentration required for each group (DMSO final concentration $<1 \%)$.

Seven-point and 28-point neuroscore tests were used to assess post-ischemic motor and behavioral deficits (modified from (Zausinger, et al., 2000)). In brief, a blinded investigator conducted the neurological tests: pre-MCAO (baseline), 2, 24, 48 and $72 \mathrm{~h}$ after reperfusion (3 day follow-up groups). The 28-point neuroscore test was broken down into sub-scores for subsequent analysis describing paw function, general condition and turning preference. At the same time-points, an individual body weight follow-up was performed. Animals with more than $25 \%$ of body weight loss were sacrificed.

Seventy-two hours after tMCAo, animals were deeply anesthetized with pentobarbital (60 $\mu \mathrm{g} / \mathrm{kg}$ Mebunat, Orion Pharma, Finland). Then, $\mathrm{T}_{2}$-weighted magnetic resonance imaging (MRI) was performed with a Varian Inova console interfaced to a $4.7 \mathrm{~T}$ horizontal magnet 
equipped with actively shielded gradient coils. A half-volume coil, driven in quadrature mode, was used for signal transmission and reception. To determine the cerebral infarct volume, $\mathrm{T}_{2}$-weighted multislice (12-14 continuous slices) images were acquired by use of double spin-echo sequence with adiabatic refocusing pulses TR $=3 \mathrm{~s}, \mathrm{TE}=80 \mathrm{~ms}, 256 \times 128$ matrix size, $35 \times 35 \mathrm{~mm}^{2}$ FOV and a slice thickness of $1 \mathrm{~mm}$. The center of the stack was positioned at $-3.2 \mathrm{~mm}$ from the bregma with the help of axial pilot images and with the aid of a rat brain atlas (Paxinos and Watson, 1986). The estimated slice positioning error between repeated scans was $<50 \%$ of the slice thickness. The total anatomical imaging time was 12 minutes. $T_{2}$ images were analyzed using in-house written Matlab software. Absolute $T_{2}$ maps were calculated and average $\mathrm{T}_{2}$ value over the lesion was determined.

\section{Histological and immunohistochemical procedures}

Once MRI was completed, anaesthetized animals were perfused transcardially with heparinized saline $(2.5 \mathrm{IU} / \mathrm{ml})$ followed by $4 \%$ paraformaldehyde in $0.1 \mathrm{M}$ phosphate buffer ( $\mathrm{PB}, \mathrm{pH}$ 7.4). Then brains were immersed in $4 \%$ paraformaldehyde in $0.1 \mathrm{M}$ PB for 24 hours, rinsed with 0.01 M PBS, cryoprotected in 30\% sucrose in PB for 2 days and frozen in liquid nitrogen-cooled isopentane. These brain specimens were stored at $-80^{\circ} \mathrm{C}$, until sectioning. Based on MRI results of the ischemic damage, the ischemic core was located at level $-1,2 \mathrm{~mm}$ to Bregma (Paxinos and Watson, 1986). A total of 60 serial sections/rat of $12 \mu \mathrm{m}$ were collected with a cryotome. Sections were used for Nissl standard and Haematoxylin-Eosin (H\&E) stainings to determine the lesion volume. To determine calcium deposits, sections were stained with the Alizarin red method (2\% in $50 \mathrm{mM}$ Tris, $\mathrm{pH} 7.6)$ and counterstained with fast green (0.5\% in $50 \mathrm{mM}$ Tris) as described elsewhere (Mahy, et al., 1999, Rodriguez, et al., 2004). Degenerating neurons were detected by Fluorojade B (FJB) fluorochrome (Schmued, et al., 1997), as follows. Sections mounted on 10\% Poly-D-lysine slides were 
sequentially immersed in $1 \% \mathrm{NaOH}$ in $80 \%$ ethanol for $5 \mathrm{~min}, 70 \%$ ethanol for $2 \mathrm{~min}$, and distilled $\mathrm{H}_{2} \mathrm{O}$ for $2 \mathrm{~min}$. They were then transferred to $0.06 \% \mathrm{KMnO}_{4}$ for $10 \mathrm{~min}$ and rinsed in distilled $\mathrm{H}_{2} \mathrm{O}$. The staining solution was prepared from a $0.01 \%$ stock solution of FJB (1M), resulting in a final dye concentration of $0.0004 \%$. After $20 \mathrm{~min}$ in the staining solution, the slides were rinsed in distilled $\mathrm{H}_{2} \mathrm{O}$, dried, and mounted with Prolong.

Immunohistochemistry was studied with the avidin-biotin peroxidase method as previously described (Rodriguez, et al., 2009, Rodriguez, et al., 2005). For neuronal and astroglial detection, sections were processed with anti-NeuN (1/150) and anti-GFAP (1/400) respectively, in 3\% normal goat serum (NGS). Anti-S100ß (1/800) was also used to detect astrocytes. Microglial cells were identified by use of IB4 diluted (1/25) in 3\% NGS. Then, all sections were incubated with ExtrAvidin-Peroxidase (1/250) before reaction with 3,3'diaminobenzidine $(0.025 \%)$ and hydrogen peroxide $(0.006 \%)$ prepared in a $50 \mathrm{mM}$ Tris- $\mathrm{HCl}$ (pH 7.6) for 10-15 min. Finally, sections were dehydrated, cleared and mounted with DPX.

Morphological and histological parameters were measured with the optical microscope software AxioVision 4 AC, (Zeiss) and analyzed by the Image Pro Plus v.5.1 image analysis system (Media Cybernetics Inc., Bethesda, MD, USA). Whole left hemispheres were studied on serial Nissl and H\&E stained coronal sections, that allow to differentiate between structures and identify the damage to be accurately quantified. Initially cortical and subcortical regions were well delimited and analyzed separately (supplementary figure 1). As such, three different affected areas were considered in each region: first, a non-infarcted zone whose tissue architecture had avoided injury and was intact; second, a necrotic zone defined as the infarct nucleus showing few scattered cells stained by NeuN immunohistochemistry; and finally, the peri-infarcted zone was defined as the remaining zone between the noninfarcted and necrotic ones. In some cases, the peri-infarcted and necrotic zones were analyzed together and defined as the entire lesioned zone. 
The areas of astrogliosis and microgliosis were measured on GFAP-immunostained and IB4stained sections, respectively, with the same image analysis system. In all cases, the contralateral hemisphere area was measured in the same sections, to calculate the effects of histological procedures on tissue size, and correct for variability in individual brain size and tissue shrinkage.

Stereological methods were used to quantify the number of cells at the core of the lesion. The Optical Fractionator method was used. Non-infarcted, peri-infarcted and necrotic areas were outlined at cortical and subcortical levels at 2.5x magnification on arbitrary uniform random (AUR) coronal sections, located between $-0.8 \mathrm{~mm}$ and $-1.8 \mathrm{~mm}$ to Bregma (Paxinos and Watson, 1986). Individual cells were then viewed and counted at 40x within AUR sampled sites chosen by the Mercator Pro 7.0 software (ExploraNova, La Rochelle, France). Neurons and astrocytes were counted on NeuN and GFAP immunostained sections respectively, whereas microglia cells were counted on IB4 stained sections. For each cell type 4 serial sections were analyzed per rat.

Double immunofluorescence labeling was carried out using specifics markers for neurons (anti-NeuN; 1/150), astrocytes (anti-GFAP; 1/750), microglia (anti-CD11b; 1/100 or IB4; 1/25) and T-cells (anti-CD3; 1/100). Antibodies against the IgG of appropriated species and conjugated with the fluorescent dyes AlexaFluor-555 (1/300), AlexaFluor-488 (1/300) or FITC (1/250) (Invitrogen; Carlsbad, CA) were used as secondary antibodies. Confocal images were acquired by a Leica TCS SL laser scanning confocal spectral microscope (Leica Microsystems Heidelberg GmbH, Mannheim, Germany) and image analysis was done with ImageJ 1.39u (Nathional Institutes of Health, USA). The number of cells showing double immunostaining was estimated by counting of cells on 3 random confocal photomicrographs $(n=60$ cells/image). Results are given as a percentage of the total number of cells. 


\section{Statistical Analysis}

Q-Q plots were calculated to test the normal distribution of data and variance homogeneity was checked by Levene's test. Most analyses were performed by one-way analysis of variance (ANOVA) followed by the post-hoc least significant difference test to compare differences between groups. When normality was not reached, the non-parametric Kruskal-Wallis (KW) test and then the Mann-Whitney U test were used to compare values for all groups. For the study of the blood-brain-barrier breakdown, standard deviation and mean values between control and ischemia brain tissue were compared with the F-test and Student-t tests respectively.

For the analysis of Neuroscore and MRI, differences among means were analyzed by one-way ANOVA followed by Dunnet's post hoc test (comparison with the vehicle treated group) or by the non-parametric KW test (between groups). Additional within group analyses were performed after original data analysis by using linear mixed models to fit data in which the rat was considered as a random effect. An autoregressive error was added into the model to control the time course of each parameter. The significance of the treatment, time and treatment by time effects were tested using the F-Wald test (Brown and Prescott, 1999). The post-hoc paired differences of means were evaluated by correcting the type-I error rate (Edwards and Berry, 1987) to guarantee an overall type-I error rate of 5\%.

To evaluate morphological and histological results, a double-blind method was used. Original data of area sizes were corrected by control of non-injured area sizes to minimize the effects of tissue sectioning deflection. Differences among means were analyzed by multifactorANOVA followed by the LSD post-hoc test. To correct for brain size variability, the whole hemisphere area size was used as covariate. To avoid misinterpretation of results, variance components were also analyzed in all cases. Only data from animals surviving until the end of the study were included in the statistical analysis. In vitro differences between means were 
analyzed by using one-way ANOVA followed by the LSD post hoc test.

All values are given as mean \pm standard deviation (SD) or standard error of mean (SEM).

Values of $\mathrm{p}<0.05$ where considered significant. Analyses were performed with the Statgraphics 5.0 (STSC Inc., Rockville, MD) and StatsDirect (StatsDirect Ltd Altrincham, UK) statistical packages. 


\section{RESULTS}

\section{BV2 cell activation with LPS+IFN $\gamma$ enhances $K_{\mathrm{ATP}}$ channel expression}

To investigate the direct Gbc effects on microglia, we activated and treated with Gbc murine BV2 microglia. We first assessed by RT-PCR the expression of SUR1, SUR2A, SUR2B, Kir6.1 and Kir6.2, before and after activation with LPS+IFN $\gamma$. Here we used total RNA from murine pancreas and lung, which constitutively express $\mathrm{K}_{\mathrm{ATP}}$ channels, as positive controls, and total RNA from HEK293 cells as negative control. After reverse transcription with oligodT primers and amplification, electrophoresis showed amplicons of the predicted size for SUR1, Kir6.1 and Kir6.2. (Figure 1A, E, I). Amplicons for Kir6.1 and Kir6.2 were at higher quantities in BV2 cells activated with LPS+IFN $\gamma$ than in non-activated cells. We could not reproduce SUR2A and SUR2B results because of the low amount of DNA from their amplicons, which was at the limit of detection of the technique (data not shown)

We then quantified the relative protein concentration of the channel components by Westernblot. We found specific bands for SUR1, Kir6.1 and Kir6.2 proteins at predicted sizes. When quantified, all three proteins had higher concentrations $48 \mathrm{~h}$ hours after LPS+IFN $\gamma$ activation, with a 5.21-fold increase for SUR1, 3.26-fold for Kir6.1, and 1.38-fold for Kir6.2 (Figure 1B, F, J). Immunocytochemistry confirmed these results. In control BV2 cells, all three proteins had a weak basal staining (Figure 1C, G, K). After activation both the number of cell processes and specific labeling of SUR1, Kir6.1 and Kir6.2 increased (Figure 1D, H, L).

\section{Glibenclamide modifies activated BV2 microglia activity}

We then investigated whether Gbc directly modulates NO and pro-inflammatory cytokine production in activated BV2 microglia. We added Gbc to the media at 3 different concentrations $\left(1 \mathrm{nM}, 10^{-3} \mathrm{nM}\right.$ or $\left.10^{-5} \mathrm{nM}\right) 30$ min prior to activation (pre-treatment) or 24 hours after activation (post-treatment). At 48 hours LPS+IFN $\gamma$ increased the NO production 
of BV2 cells 6-fold and Gbc did not modified this increase. Under these same conditions, LPS+IFN $\gamma$ increased TNF $\alpha$ release in the medium ( $\mathrm{t}=-5.6 ; \mathrm{p}<0.01)$, which resulted $45 \%$ higher after pre-treatment with $10^{-5} \mathrm{nM} \mathrm{Gbc}\left(\mathrm{F}_{19,3}=3.49 ; \mathrm{p}=0.04\right)$. By contrast, Gbc $1 \mathrm{nM}$ decreased TNF $\alpha$ release by quiescent BV2 cells ( $\mathrm{t}=-3.53 ; \mathrm{p}=0.02)$ (Figure $2 \mathrm{~A}, \mathbf{B}$ ).

Activation of BV2 microglia involves a morphological change characterized spherical quiescent cells losing their spherical shape and the development of cell processes that are directly related to the phagocytic capacity of the cells. BV2 cell shape analysis performed 48 hours after incubation with LPS+IFN $\gamma$ showed a higher perimeter/area ratio, which confirmed the activation state of the cells $(\mathrm{KS}=2.7 ; \mathrm{p}<0.01) .10^{-5} \mathrm{nM}$ and $10^{-3} \mathrm{nM}$ Gbc pre-treatment induced an increase in the perimeter/area ratio values of activated cells $(\mathrm{KW}=31.8 ; \mathrm{p}<0.01)$ (Figure 2C, G). Gbc post-treatment required higher concentrations to produce similar results $\left(10^{-3} \mathrm{nM}\right.$ and $\left.1 \mathrm{nM} ; \mathrm{KW}=50.6 ; \mathrm{p}<0.01\right)$ (Figure 2D).

Finally, we quantified the phagocytic capacity of activated BV2 microglia. 48 hours after activation the percentage of phagocytic cells increased 2, 5, 15 and $30 \mathrm{~min}$ after incubation in presence of fluosphere $(\mathrm{KW}=7 ; \mathrm{p}<0.01)$. Five minutes after fluosphere incubation, Gbc pretreatment increased the percentage of phagocytic cells $\left(\mathrm{F}_{11,3}=6.20 ; \mathrm{p}=0.01\right)$ (Figure 2E, G). At this time point, $10^{-5} \mathrm{nM}$ and $1 \mathrm{nM} \mathrm{Gbc}$ both increased the percentage of phagocytic cells, but $1 \mathrm{nM} \mathrm{Gbc}$ produced the maximal effect which remained stable during the 30 minutes of the study. In contrast, Gbc post-treatment did not modify the phagocytic capacity at any dose (Figure 2F).

\section{Glibenclamide improves the neurological outcome of tMCAo rats.}

We injected $\left[{ }^{3} \mathrm{H}\right] \mathrm{Gbc}(100 \mu \mathrm{Ci})$ i.p. to animals 16 hours after permanent MCAo to investigate whether Gbc enters the ischemic rat brain after peripheral administration. Two hours later, the

specific $\left[{ }^{3} \mathrm{H}\right] \mathrm{Gbc}$ binding to the ischemic hemisphere was significantly greater than in the 
control hemisphere $(t=7.7, p=0.0014)$, whereas the value of the uninjured hemisphere was similar to non-radioactive tissue $(\mathrm{t}=3.445 ; \mathrm{p}=0.0749)$ (Figure 3A). Only $0.025 \%$ of injected $\left[{ }^{3} \mathrm{H}\right] \mathrm{Gbc}$ entered the control brain, but permanent MCAo-induced blood-brain barrier breakdown increased this value to $0.077 \%$, which resulted in binding values similar to those of heart and kidney (data not shown). Thus, peripherally administered Gbc reaches the ischemic brain, where it could have a specific pharmacological effect.

To assess whether Gbc improves the motor and behavioral recovery after stroke, 4 groups of 60 min tMCAo animals received $0 \mu \mathrm{g}$ (vehicle group), $0.06 \mu \mathrm{g}, 0.6 \mu \mathrm{g}$ and $6 \mu \mathrm{g}$ Gbc. Then, we conducted double-blind 7-point and 28-point neuroscore tests in all animals at the following times: pre-tMCAo (baseline), $2 \mathrm{~h}, 24 \mathrm{~h}, 48 \mathrm{~h}$ and $72 \mathrm{~h}$ after reperfusion. We found an overall reduction of 7-point neuroscore test values $2 \mathrm{~h}$ after the occlusion. When compared with the vehicle group, none of the Gbc-treated groups improved the 7-point neuroscore values at any time point. However, when we analyzed data of each group as a time-course, we detected a $25 \%$ score improvement at $72 \mathrm{~h}$ in the $0.6 \mu \mathrm{g}$ Gbc-treated animals, compared with the $24 \mathrm{~h}$ time point $(\mathrm{t}=3.65, \mathrm{p}=0.0076)($ Figure 3B $)$.

We also found an overall reduction of the 28-point test values $2 \mathrm{~h}$ after the occlusion and, compared with vehicle, Gbc treatments did not improved those values at any time-point. Vehicle, $0.06 \mu \mathrm{g}, 0.6 \mu \mathrm{g}$ and $6 \mu \mathrm{g}$ Gbc-treated animals improved their score at $72 \mathrm{~h}$ over their $24 \mathrm{~h}$ values $(\mathrm{t}=3.92, \mathrm{p}=0.0097 ; \mathrm{t}=3.89, \mathrm{p}=0.0113 ; \mathrm{t}=4.99, \mathrm{p}=0.0002$, and $\mathrm{t}=3.83, \mathrm{p}=0.0142$ respectively). In animals treated with $0.6 \mu \mathrm{g} \mathrm{Gbc}$, this recovery was higher and already significant $48 \mathrm{~h}$ after tMCAo ( $\mathrm{t}=3.64, \mathrm{p}=0.0244$, data not shown).

$72 \mathrm{~h}$ after tMCAo, we identified brain damage and quantified cortical, subcortical and total infarct volumes by $\mathrm{T}_{2}$-MRI, to determine whether this Gbc-induced motor recovery is connected with a reduction of brain lesion (Figure 3C, D). None of the doses of Gbc modified these volumes when compared with the vehicle group. Under our experimental 
conditions, MRI did not allowed to discrimination between the peri-infarcted and necrotic zones within the lesion volume, and we could not perform accurate quantification of these volumes due to the limitations of the technique. We then investigated the putative neuroprotective effect of Gbc in the tMCAo lesion through a histological approach.

\section{Glibenclamide decreases tMCAo-induced neuronal loss and brain calcification}

According to MRI results, the whole ischemic lesion studied on H\&E stained sections only showed a slight reduction, which did not reach significance with any dose of Gbc when compared with the vehicle group (Supplementary figure 1). However, at the ischemic focus (from -0.8 to $-1.8 \mathrm{~mm}$ to bregma; Figure $\mathbf{4 F}$ ) this slight reduction reflected significant changes of the peri-infarcted and the necrotic volumes as described below.

Detailed analysis of the total necrotic volume examined by Neu-N immunohistochemistry, defined as the volume lacking Neu-N-positive cells, showed differences between treated groups (Figure 4A-D). Dose of Gbc of $0.6 \mu \mathrm{g}$ reduced the total necrotic volume compared with $0.06 \mu \mathrm{g}$ Gbc and vehicle, whereas $6 \mu \mathrm{g}$ Gbc only had differences compared with vehicle $\left(\mathrm{F}_{38,3}=5,54 ; \mathrm{p}=0.0035\right)$ (Figure 4G). At the cortical level, Gbc $0.6 \mu \mathrm{g}$ and $6 \mu \mathrm{g}$ decreased the necrotic volume compared with vehicle $\left(\mathrm{F}_{38,3}=2.91 ; \mathrm{p}=0.0480\right)$, whereas at the subcortical level only $0.6 \mu \mathrm{g}$ Gbc reduced this volume $\left(\mathrm{F}_{38,3}=4,7 ; \mathrm{p}=0.0079\right)$. This lack of modification of the whole ischemic lesion and this small decrease in necrotic volume imply an increase in the peri-infarcted volume, which resulted significant in the $0.6 \mu \mathrm{g}$ and $6 \mu \mathrm{g}$ Gbc groups $\left(\mathrm{F}_{38,3}=8.19 ; \mathrm{p}=0.0003\right)$ (Figure 4H).

To express the Gbc effects in terms of neuronal loss, we performed stereological counting on these sections. Although cell density not changed, we found a slight tendency to reduction of neuron numbers in the necrotic zone of all Gbc-treated groups $\left(\mathrm{F}_{43,3}=4,72 ; \mathrm{p}=0.073\right)$ (Figure 4J). Moreover, we observed a significant neuronal preservation in the subcortical peri-infarct 
zone in the $0.6 \mu \mathrm{g}$ and $6 \mu \mathrm{g}$ Gbc animals $\left(\mathrm{F}_{43,3}=8,01 ; \mathrm{p}=0.0038\right)$ (Figure 4K). The same was true when the necrotic and peri-infarcted zones were taken together as a total lesion volume. In this case, $0.6 \mu \mathrm{g}$ Gbc preserved more neuronal cells in the subcortical region than in the vehicle group and $0.06 \mu \mathrm{g}$ dose, while $6 \mu \mathrm{g}$ Gbc also showed greater neuronal preservation than the $0.06 \mu \mathrm{g}$ dose $\left(\mathrm{F}_{39,3}=5.3 ; \mathrm{p}=0.0041 ; \mathrm{F}_{35,3}=5.13 ; \mathrm{p}=0.0048\right)$ (Figure 4I).

We then used FJB staining to evaluate neuronal suffering and the intensity of the neurodegenerative process. In the ischemic focus $(-0.8 \mathrm{~mm}$ to bregma) of all tMCAo animals, we observed an intense FJB labeling of the cell body in several neurons of cortical and subcortical zones, particularly in the peri-infarcted zone (Figure 4E), with no clear effect of Gbc on this FJB staining pattern.

Formation of insoluble calcium phosphate complexes is strongly linked to stroke-induced calcium dyshomeostasis and neuronal loss. Thus, we studied by Alizarin red staining whether Gbc modifies the tMCAo-induced calcification at ischemic core level (Figure 5A). Gbc treatment induced a reduction of the calcium deposit diameter in the $0.6 \mu \mathrm{g}$ Gbc group $v s$ vehicle and $0.06 \mu \mathrm{g}$ Gbc group $(\mathrm{KW}=18.18$; $\mathrm{p}=0.0004$; Figure 5B). Gbc also decreased the calcium deposit number in a dose-dependent response that was significant in the cortical zone, reaching statistical significance at $\mathrm{Gbc}$ doses of $0.6 \mu \mathrm{g}$ and $6 \mu \mathrm{g}(\mathrm{KW}=10.43 ; \mathrm{p}=0.015$; Figure 5A, C). Thus, although Gbc did not modify neurodegeneration, it fosters a neuronal preservation in the ischemic core and decreases calcification. This suggests that, once the injury processes are controlled, more neurons will be preserved in the peri-infarcted zone of Gbc-treated animals.

\section{Glibenclamide does not modify tMCAo-induced astrogliosis}

We then studied the astroglial reaction associated with tMCAo in the ischemic focus by GFAP and S100ß immunohistochemistry. GFAP immunohistochemistry revealed astrocytes 
with hypertrophy and hyperplasia, as well as high GFAP immunostaining covering almost the whole lesioned hemisphere. However, we found zones lacking astrocyte labeling coincident with the cortical and subcortical necrotic zones defined by NeuN immunohistochemistry (Figure 6A, B), and their quantification showed no difference between groups (data not shown). In addition, Gbc did not modify tMCAo-induced astrogliosis or astrocyte density (Figure 6C).

S100 $\beta$ immunohistochemistry showed widespread S100 $\beta$ distribution around the necrotic zone, with the most intense immunoreactivity located in astrocytes of the corpus callosum and other areas of the white matter, in which Gbc increased S100 $\beta$ immunostaining and astrocyte hyperplasia (Figure 6D, E).

\section{Reactive microglia express $\mathrm{K}_{\mathrm{ATP}}$ channels in tMCAo rat brain}

We performed double immunolabeling and confocal microscopy at the ischemic core level ($0.8 \mathrm{~mm}$ to bregma) and used the CD3 antibody to detect $\mathrm{T}$ lymphocyte infiltration together with IB4, which stains microglia/macrophages (Figure 7B). Within the necrotic core of some animals we detected small areas with few CD3-immunopositive cells, which never co-located with any IB4 staining. Thus, although CD3-immunopositive and IB4-positive cells showed tight contacts suggesting a neuroimmune crosstalk as a response to the lesion, lymphocyte infiltration 3 days after tMCAo was small and did not interfere with IB4 labeling. Low magnification photomicrographs from IB4 stained tMCAo samples showed continuity in microgliosis reaction, and we do not observed boundary between the necrotic core and periinfacrt region (Figure 7C, D). Nonetheless, morphology of IB4-labelled cells changed with their location and proximity to the infarct core of the lesion. The small cell body and several ramifications of resting microglia in healthy tissue (Figure 7E) changed progressively into a larger cell body and a more ramified reactive morphology with numerous processes in the 
peri-infarcted zone (Figure 7F). In the area between the peri-infarcted and necrotic zones, positive cells had a mixed reactive-amoeboid morphology (Figure 7G). We observed fully amoeboid cells within the necrotic core (Figure 7H), in which we found massive loss of neurons and absence of GFAP-immunopositive cells. Gbc treatment did not modify the size of the zone occupied by tMCAo-induced reactive cells. Nonetheless, when we analyzed cell density we found a significant overall group effect in the cortical $(\mathrm{t}=19.2, \mathrm{p}=0.0008)$ and subcortical ( $\mathrm{t}=16.1, \mathrm{p}=0.009)$ zones of tMCAo groups (Figure 7A), but Gbc presented no effects.

To locate the cell expression of $\mathrm{K}_{\mathrm{ATP}}$ channel components, we performed double immunohistochemical labeling with anti-SUR1, anti-SUR2B, or anti-Kir6.2 antibodies combined with anti-CD11b antibody as microglia/macrophage marker, with anti-NeuN as neuronal marker and with anti-GFAP as astroglial marker. Co-location with anti-CD11b antibody indicated that reactive microglia within the necrotic zone expressed Kir6.2 $(32.7 \pm 2.5 \%)$, SUR1 $(40 \pm 2.7 \%)$ and/or SUR2B (39 $\pm 7.5 \%)$ (Figure 8). Anti-SUR1 and antiSUR2B antibodies also labeled some hippocampal and hypothalamic neurons and some astrocytes in the peri-infarcted zone, whereas Kir6.2 labeling did not clearly co-locate with GFAP immunolabeling in the ischemic brain (raw data not shown). 


\section{DISCUSSION}

In this study we identified the $\mathrm{K}_{\mathrm{ATP}}$ channel as a key player in controlling microglia-mediated neuroprotection in focal cerebral ischemia. In our in vitro experiments we demonstrated that $\mathrm{K}_{\text {ATP }}$ channel subunit expression upregulated after LPS+IFN $\gamma$ activation, and that its blockade increased reactive morphology, $\mathrm{TNF} \alpha$ release and the phagocytic capacity of activated microglia. Furthermore, in the tMCAo rat model, we found that the improved neurological outcome and neuronal preservation in the necrotic core due to Gbc treatment did not correlated with the volume of lesion and astroglial reaction, and that resident amoeboid microglia are the main cell population in the necrotic zone. Also, reactive microglial cells express SUR1, SUR2B and Kir6.2 proteins that can assemble in functional $\mathrm{K}_{\mathrm{ATP}}$ channels. Thus, $\mathrm{K}_{\mathrm{ATP}}$ channels should directly participate in the control of microglial reactivity, with Gbc treatment resulting in a strengthening of the neuroprotective role of microglia/macrophages in the early stages of stroke. It is interesting to note that the Gbc doses used here are substantially lower than the ones used in previous studies presenting neuroprotective effects (Simard, et al., 2009).

In our model of tMCAo, low doses of Gbc administered at 6, 12 and 24 hours after reperfusion reached the ischemic brain and significantly reduced the lesion's severity, as it improved motor neurological outcome and triggered neuronal preservation in the periinfarcted region. Nonetheless, the volume of lesion measured by MRI did not reflect this Gbcmediated neuroprotection. Most rodent models of stroke focus on the outcome measurement of lesion size in terms of infarct volume and brain edema. Within the first 3 days of lesion, the methodological approach and accuracy in these measurements are essential, since brain edema development may lead to overestimation of infarct volume (Lin, et al., 1993). This accuracy reaches crucial importance in the assessment of drugs activity, since their neuroprotective effects may not be reflected by these two parameters (Walberer, et al., 2010). 
Under our conditions, we used MRI to assess changes in the lesion's volume size, but this approach cannot give a precise indication of the severity of the injury (Simard, et al., 2010) and is not accurate enough to measure the necrotic core of the lesion. When we included histological methods, measurement of the necrotic and peri-infarct zones (Lin, et al., 1993) and neuronal counts defined the morphological and cellular bases of the motor function improvement induced by $\mathrm{K}_{\mathrm{ATP}}$ channel blockade.

The fate of the ischemic penumbra during the early steadies of the injury is considered the crucial element for stroke recovery (Furlan, et al., 1996) since in the necrotic zone astrocytes and neurons are determined to die. The small size of the cerebral area occupied by CD3immunopositive cells here observed for lymphocytes suggests little infiltration of blood cells 3 days after tMCAo. Moreover, infiltrated macrophages and granulocytes are proposed to not play major roles in the progression of ischemic neuronal damage for up to 16 hours, whereas reactive microglia are already detected in the zone from 6h post-tMCAo (Mabuchi, et al., 2000). Furthermore, a transition of monocyte-derived cells into microglia is a very rare event that only occurs under highly defined host conditions (Mildner, et al., 2007). Thus, microglial activity in the necrotic core would be crucial in determining the fate of the ischemic tissue. If true, the Gbc-induced neuronal preservation and functional recovery here found would reflect an enhancement of the neuroprotective microglial activity in the necrotic core.

Transcriptional upregulation of SUR1 in the ischemic brain is related to $\mathrm{NC}_{\mathrm{Ca}-\mathrm{ATP}}$ channels of neurons, astrocytes and capillary endothelial cells of the peri-infarct region (Simard, et al., 2006). As activation of $\mathrm{NC}_{\mathrm{Ca}-\mathrm{ATP}}$ channels in astrocytes causes cell blebbing characteristic of cytotoxic edema, the Gbc-mediated reduction of infarct volume in permanent MCAo animals has been linked with blockade of these channels, whereas the involvement of $\mathrm{K}_{\mathrm{ATP}}$ channels in the process has been ruled out (Simard, et al., 2009). However, those studies did not assess the ischemia-induced expression changes of the trpm4 gene, the pore-forming subunit of 
$\mathrm{NC}_{\mathrm{Ca}-\mathrm{ATP}}$ channels (Simard, et al., 2010) and, despite the massive neuronal loss, immunoblots revealed no concentration changes of Kir6.1 and Kir6.2 proteins in the ischemic core (Simard, et al., 2006). Our findings complete these results and argue for a contribution of $\mathrm{K}_{\mathrm{ATP}}$ channels to the neuroprotective effects of Gbc by reducing the lesion's severity. Thus, we found that activation of microglia enhances SUR1, Kir6.1 and Kir6.2 protein expression, and that amoeboid microglia express $\mathrm{K}_{\mathrm{ATP}}$ channels in the necrotic core of the lesion. This upregulation contributed to the enhancement of SUR1 found by Simard and cols. (2006), and helped compensate for a putative decrease in Kir6.1 and Kir6.2 subunits due to the massive neuronal loss in the necrotic zone. It also explains the increased Kir6.1 and Kir6.2 expression in absence of the further neuronal damage in brain hypoxia described by other authors (Yamada, et al., 2001).

Activation of $\mathrm{K}_{\mathrm{ATP}}$ channels results in cell membrane hyperpolarization that may modulate microglial response to activation signals. Thus, the effects of an external stimulus on microglia are likely to be modulated at each moment by the number and degree of activated $\mathrm{K}_{\mathrm{ATP}}$ channels, which in turn may depend, as in pancreatic $\beta$-cells, on the ATP/ADP cell ratio and ultimately on its energy level (Nichols, 2006). Our findings reveal a direct influence of $\mathrm{K}_{\mathrm{ATP}}$ channels on the phagocytic capacity and $\mathrm{TNF} \alpha$ release of in vitro microglia, and also argue for Gbc enhancement of microglia reactivity in the early stages of stroke. Voltage- and calcium-dependent potassium channels participate in microglia functions, such as scavenging and neuroprotective actions (Eder, 1998). As such, blockade of $\mathrm{K}^{+}$channels inhibits the respiratory burst and the morphological changes associated with in vitro microglia activation (Khanna, et al., 2001). Here we provide evidence that Gbc increases the reactive morphology and phagocytic capacity of BV2 microglia activated with LPS+IFN $\gamma$. Microglia phagocytic abilities are essential for the clearance of cell debris and toxic compounds of the lesioned tissue, which underlies neuroprotection (Polazzi and Monti, 2010). In addition, dying 
polymorphonuclear neutrophils (PMNs) infiltrated in the site of lesion, mediate neurotoxicity by the release of toxic intracellular compounds (Denes, et al., 2007, Weston, et al., 2007) and that, consequently, prompt phagocytosis of apoptotic PMNs by microglia might prevent the secretion of toxic compounds. Thus, clearance of PMNs from the nervous tissue might be an effective strategy to protect neurons from PMN neurotoxicity (Neumann, et al., 2008). Also the $\mathrm{K}_{\mathrm{ATP}}$ channel blockade slightly enhances neuronal loss in the necrotic core and these microglial cells are more efficient in clearing generated apoptotic cell debris, and reduces the secretion of pro-inflammatory cytokines (Magnus, et al., 2001), and chemoattractants and T lymphocyte recruitment (Chan et al 2006). Overall, this data suggest that cell debris clearing will provide an optimal environment for neuroprotection in the surrounding tissue.

Furthermore, in hypoxia-ischemia, acute brain damage or excitotoxicity, microglia reaction includes a phagocytic response to the formation of calcium deposits (Herrmann, et al., 1998). Extension of calcification after hypoxia-ischemia in a brain area depends on the intensity of the acute phase and on the characteristics of each area of pathology (Lievens, et al., 2000, Nonoda, et al., 2009, Rodriguez, et al., 2001). Here we found a Gbc-induced decrease in ischemic brain calcification with a reduced size and number of deposits, which represents a reduction in tMCAo-induced neuronal suffering and may be related to boosted microglial phagocytic activity.

Reactive microglial cells also release a broad panel of potentially neuroprotective factors. One of these factors is TNF $\alpha$ whose production reflects the complex roles of microglial activity with conflicting effects. We herein found that Gbc increases TNF $\alpha$ but does not increases NO release of BV2 microglia activated with LPS+IFN $\gamma$. This result argues for a specific Gbc influence on TNF $\alpha$ release. TNF $\alpha$ secretion is crucial for autocrine fast microglial activation with cytotoxic effects. For example, microglia activation by aggregated $\beta$-amyloid or lipopolysaccharide increases $\mathrm{TNF} \alpha$ secretion and renders them cytotoxic (Butovsky, et al., 
2005). However, in $\mathrm{TNF} \alpha$ knock-out mice NO-mediated microglial activation appears delayed, results in further exacerbated non-specific microgliosis (Blais and Rivest, 2004) and leads to the amplification of secondary excitotoxicity (Glezer, et al., 2007). Actions of TNF $\alpha$ leading to neuronal death or survival are dose dependent (Bernardino, et al., 2008), since it activates two specific receptors: TNFR1, with an intracellular death domain, and TNFR2 with higher affinity and mainly involved in neuroprotection (Fontaine, et al., 2002). These two receptors are key elements in modulating neuronal sensitivity to ischemia, with microglialderived TNF $\alpha$ being crucial to determining the survival of endangered neurons in the acute phase of focal cerebral ischemia (Lambertsen, et al., 2009). Microglial TNFR2 is proposed to mediate the counter-regulatory response activated in neuropathological conditions (Veroni, et al., 2010). In addition, TNF $\alpha$ is proposed as the molecular mediator of the microglialmediated synapse removal, likely to be important in remodeling of neuronal circuits in the ischemic brain to ensure function (Wake, et al., 2009) and involved in remyelination processes (Arnett, et al., 2003). Consequently, TNF $\alpha$ actions leading to neuronal death or survival on neuronal damage are largely dependent on the context, timing, and dosage of TNF $\alpha$ activity (Lenzlinger, et al., 2001, Rolls 2008). Thus, often, a clear distinction between cytokines that are either harmful or beneficial cannot be established, since the primarily cytotoxic pro-inflammatory cytokines IL-1 $\beta$ and TNF $\alpha$ released from activated microglia may evoke a neuroprotective or pro-myelin regenerative response. For example, TNF $\alpha$ protects neurons against amyloid-beta-peptide-mediated toxicity (Barger, et al., 1995) under pathological conditions, and has a role in homoeostatic synaptic scaling under physiological conditions (Stellwagen and Malenka, 2006). In this regard, acute injury such as trauma or stroke activated microglia and their pro-inflammatory mediators may primarily have a neuroprotective role (Neumann, et al., 2006) and therefore, anti-inflammatory treatment within the protective time window of microglia would be counterproductive. 
Continuous crosstalk mediated by several signaling molecules, takes place between neurons, microglia and astrocytes, differently regulating their relationships in both health and disease (Polazzi and Monti, 2010). In this regard, we here found a Gbc-induced increase of S100 $\beta$ in reactive astrocytes of the white mater, probably due to the $\mathrm{NC}_{\mathrm{Ca}-\mathrm{ATP}}$ channel blockade (Simard, et al., 2009), which may influence microglial-mediated neuroprotection. Released S100 $\beta$ modifies astrocytic, neuronal and microglial activities, whose effects depend on its extracellular concentration and the expression of the specific receptor RAGE. At micromolar concentrations, S100 $\beta$ upregulates TNF $\alpha$ expression in activated microglia (Bianchi, et al., 2010). In addition, factors that modulate microglial reactivity, such as intracellular calcium concentration or TNF $\alpha$, modify the RAGE response to S100 $\beta$ (Edwards and Robinson, 2006) in a crosstalk that integrates these signaling systems. Thus, microglia reaction directly interacts with the concomitant astroglial reaction and the factors that determine this interaction, such as $\mathrm{TNF} \alpha$ and $\mathrm{S} 100 \beta$ participate in the regulation of the activated phenotype of microglia after injury.

Finally, the peak of microglial activation occurs at seven days after stroke and remains activated for many weeks after tMCAo (Thored, et al., 2009), with a dual role in the early and late stages of stroke (Neumann, et al., 2006). Activated microglia can initially promote phagocytosis and brain regeneration, to then lose this protective phenotype when the injury progresses, with a persistent pro-inflammatory cytokine production (Butovsky, et al., 2005, Rolls, et al., 2008). Thus, microglia activity enhancement induced by low doses of Gbc may anticipate the peak of activation and is probably transient, since Gbc boosts the microglial activity previous to the peak of activation and is metabolized within a few hours. If this were true, Gbc would foster the early microglial neuroprotective activity, but not the late cytotoxic one. To test this hypothesis, further experiments are necessary assessing the neuronal preservation and functional improvement of tMCAo rats at longer survival times. 
In conclusion, the present findings demonstrate that Gbc improves functional neurological outcome in stroke, accompanied by neuron preservation in the core of the ischemic brain, and that the proposed stroke therapy aimed at SUR1 also involves microglial $\mathrm{K}_{\mathrm{ATP}}$ channels. Moreover, the effects of Gbc on microglial activity identify $\mathrm{K}_{\mathrm{ATP}}$ channels as a key target for modulating the neuroprotective role of microglia in the acute phase after focal cerebral ischemia. Therefore, our data clarify the mechanism of action of Gbc in stroke, and point out to microglia as a powerful regulator of neuronal survival. This also provides new therapeutic avenues for the treatment of other neurological disorders that involve microglia. 


\section{ACKNOWLEDGEMENTS}

This research was supported by grants SAF2008-01902 and PET2007-0450 from the Ministerio de Ciencia e Innovación, and by grant 2009SGR1380 from the Generalitat de Catalunya (Autonomous Government), Spain. Neurotec Pharma also financed part of the study. F.J.O. holds a fellowship from Spanish Ministerio de Educación.

Contributions to the work: NM and MJR got financial support for the study; FJO, MP, NM and MJR designed the research study; FJO, JG-B, JFE-P and MB, performed the research, FJO, JLC, MP and MJR analyzed and discussed the data; FJO, NM \& MJR wrote the paper.

\section{DISCLOSURES}

M.P., N.M. and M.J.R. hold an EU patent (No. WO2006/000608) exploited by Neurotec Pharma. All three authors hold shares in Neurotec Pharma, M.P. is the C.E.O. of the company and N.M. and M.J.R. are scientific advisors. The other authors report no disclosures. 


\section{REFERENCES}

Acarin, L., Gonzalez, B., and Castellano, B., 2000. Neuronal, astroglial and microglial cytokine expression after an excitotoxic lesion in the immature rat brain. Euro $\mathrm{J}$ Neurosc 12, 3505-3520.

Aguilar-Bryan, L., Nichols, C. G., Wechsler, S. W., Clement, J. P., Boyd, A. E., González, G., Herrera-Sosa, H., Nguy, K., Bryan, J., and Nelson, D. A., 1995. Cloning of the beta cell high-affinity sulfonylurea receptor: a regulator of insulin secretion. Science 268, 423-426.

Arnett, H. A., Wang, Y., Matsushima, G. K., Suzuki, K., and Ting, J. P.-Y., 2003. Functional genomic analysis of remyelination reveals importance of inflammation in oligodendrocyte regeneration. J Neurosci 23, 9824-9832.

Ashcroft, F. M., Kakei, M., Kelly, R. P., and Sutton, R., 1987. ATP-sensitive K+ channels in human isolated pancreatic B-cells. FEBS Lett 215, 9-12.

Ashford, M. L., Boden, P. R., and Treherne, J. M., 1990. Glucose-induced excitation of hypothalamic neurones is mediated by ATP-sensitive K+ channels. Pflugers Arch 415, 479-483.

Barger, S. W., Van Eldik, L. J., and Mattson, M. P., 1995. S100ß protects hippocampal neurons from damage induced by glucose deprivation. Brain Res 677, 167-170.

Bernardino, L., Agasse, F., Silva, B., Ferreira, R., Grade, S., and Malva, J. O., 2008. Tumor necrosis factor- $\alpha$ modulates survival, proliferation, and neuronal differentiation in neonatal subventricular zone cell cultures. Stem Cells 26, 2361-2371.

Bianchi, R., Giambanco, I., and Donato, R., 2010. S100B/RAGE-dependent activation of microglia via NF-kappaB and AP-1 Co-regulation of COX-2 expression by S100B, IL-1 beta and TNF-alpha. Neurobiol Aging 31, 665-677. 
Blais, V., and Rivest, S., 2004. Effects of TNF- $\alpha$ and IFN- $\gamma$ on nitric oxide-induced neurotoxicity in the mouse brain. J Immunol 172, 7043-7052.

Bradford, M. M., 1976. A rapid and sensitive method for the quantitation of microgram quantities of protein utilizing the principle of protein-dye binding. Anal Biochem 72, 248-254.

Brown, H., and Prescott, R., 1999. Applied mixed models in medicine. John Wiley \& Sons, Chichester.

Butovsky, O., Talpalar, A. E., Ben-Yaakov, K., and Schwartz, M., 2005. Activation of microglia by aggregated beta-amyloid or lipopolysaccharide impairs MHC-II expression and renders them cytotoxic whereas IFN-gamma and IL-4 render them protective. Mol Cell Neurosci 29, 381-393.

Chen, M., Dong, Y., and Simard, J. M., 2003. Functional coupling between sulfonylurea receptor type 1 and a nonselective cation channel in reactive astrocytes from adult rat brain. J Neurosci 23, 8568-8577.

Clement, J. P., Kunjilwar, K., Gonzalez, G., Schwanstecher, M., Panten, U., Aguilar-Bryan, L., and Bryan, J., 1997. Association and stoichiometry of K(ATP) channel subunits. Neuron 18, 827-838.

Denes, A., Vidyasagar, R., Feng, J., Narvainen, J., McColl, B. W., Kauppinen, R. A., and Allan, S. M., 2007. Proliferating resident microglia after focal cerebral ischaemia in mice. J Cereb Blood Flow Metab 27, 1941-1953.

Eder, C., 1998. Ion channels in microglia (brain macrophages). Am J Physiol 275, C327C342.

Edwards, D., and Berry, J. J., 1987. The efficiency of simulation-based multiple comparisons. Biometrics 43, 913-928. 
Edwards, M. M., and Robinson, S. R., 2006. TNF alpha affects the expression of GFAP and S100B: implications for Alzheimer's disease. J Neural Transm 113, 1709-1715.

Fontaine, V., Mohand-Said, S., Hanoteau, N., Fuchs, C., Pfizenmaier, K., and Eisel, U., 2002. Neurodegenerative and neuroprotective effects of tumor Necrosis factor (TNF) in retinal ischemia: opposite roles of TNF receptor 1 and TNF receptor 2. J Neurosci 22, RC216.

Furlan, M., Marchal, G., Viader, F., Derlon, J. M., and Baron, J. C., 1996. Spontaneous neurological recovery after stroke and the fate of the ischemic penumbra. Ann Neurol. 40, 216-226.

Glezer, I., Simard, A. R., and Rivest, S., 2007. Neuroprotective role of the innate immune system by microglia. Neuroscience $147,867-883$.

Graeber, M. B., and Streit, W. J., 2010. Microglia: biology and pathology. Acta Neuropathol $119,89-105$.

Green, L. C., Wagner, D. A., Glogowski, J., Skipper, P. L., Wishnok, J. S., and Tannenbaum, S. R., 1982. Analysis of nitrate, nitrite, and $\left[{ }^{15} \mathrm{~N}\right]$ nitrate in biological fluids. Anal Biochem 126, 131-138.

Hanisch, U., and Kettenmann, H., 2007. Microglia: active sensor and versatile effector cells in the normal and pathologic brain. Nat Neurosci 10, 1387-1394.

Herrmann, G., Stünitz, H., and Nitsch, C., 1998. Composition of ibotenic acid-induced calcifications in rat substantia nigra. Brain Res 786, 205-214.

Khanna, R., Roy, L., Zhu, X., and Schlichter, L. C., 2001. $\mathrm{K}^{+}$channels and the microglial respiratory burst. Am J Physiol 280, C796-C806.

Kim, S. U., and de Vellis, J., 2005. Microglia in health and disease. J. Neurosci. Res. 81, 302313. 
Kitamura, Y., Takata, K., Inden, M., Tsuchiya, D., Yanagisawa, D., Nakata, J., and Taniguchi, T., 2004. Intracerebroventricular injection of microglia protects against focal brain ischemia. J Pharmacol Sci 94, 203-206.

Lalancette-Hébert, M., Gowing, G., Simard, A., Weng, Y. C., and Kriz, J., 2007. Selective ablation of proliferating microglial cells exacerbates ischemic injury in the brain. $\mathbf{J}$ Neurosci 27, 2596-2605.

Lambertsen, K. L., Clausen, B. H., Babcock, A. A., Gregersen, R., Fenger, C., Nielsen, H. H., Haugaard, L. S., Wirenfeldt, M., Nielsen, M., Dagnaes-Hansen, F., Bluethmann, H., Faergeman, N. J., Meldgaard, M., Deierborg, T., and Finsen, B., 2009. Microglia protect neurons against ischemia by synthesis of tumor necrosis factor. J Neurosci 29, 1319-1330.

Lenzlinger, P. M., Morganti-Kossmann, M. C., Laurer, H. L., and McIntosh, T. K., 2001. The duality of the inflammatory response to traumatic brain injury. Mol Neurobiol 24, 169-181.

Levin, B. E., 2001. Glucosensing neurons do more than just sense glucose. Int J Obes Relat Metab Dis 25, 568-572.

Lievens, J. C., Bernal, F., Forni, C., Mahy, N., and Kerkerian-Le Goff, L., 2000. Characterization of striatal lesions produced by glutamate uptake alteration: cell death, reactive gliosis, and changes in GLT1 and GADD45 mRNA expression. Glia 29, 222232.

Lin, T. N., He, Y. Y., Wu, G., Khan, M., and Hsu, C. Y., 1993. Effect of brain edema on infarct volume in a focal cerebral ischemia model in rats. Stroke 24, 117-121.

Mabuchi, T., Kitagawa, K., Ohtsuki, T., Kuwabara, K., Yagita, Y., Yanagihara, T., Hori, M., and Matsumoto, M., 2000. Contribution of microglia/macrophages to expansion of 
infarction and response of oligodendrocytes after focal cerebral ischemia in rats. Stroke 31, 1735-1743.

Magnus, T., Chan, A., Grauer, O., Toyka, K. V., and Gold, R., 2001. Microglial phagocytosis of apoptotic inflammatory $\mathrm{T}$ cells leads to down-regulation of microglial immune activation. J Immunol 167, 5004-5010.

Mahy, N., Prats, A., Riveros, A., Andrés, N., and Bernal, F., 1999. Basal ganglia calcification induced by excitotoxicity: an experimental model characterised by electron microscopy and X-ray microanalysis. Acta Neuropathol 98, 217-225.

McLarnon, J. G., Franciosi, S., Wang, X., Bae, J. H., Choi, H. B., and Kim, S. U., 2001. Acute actions of tumor necrosis factor- $\alpha$ on intracellular $\mathrm{Ca}^{2+}$ and $\mathrm{K}^{+}$currents in human microglia. Neuroscience 104, 1175-1184.

Mikhailov, M. V., Campbell, J. D., De Wet, H., Shimomura, K., Zadek, B., Collins, R. F., Sansom, M. S. P., Ford, R. C., and Ashcroft, F. M., 2005. 3-D structural and functional characterization of the purified $\mathrm{K}_{\mathrm{ATP}}$ channel complex Kir6.2-SUR1. EMBO J 24, 4166-4175.

Mikhailov, M. V., Mikhailova, E. A., and Ashcroft, S. J., 2001. Molecular structure of the glibenclamide binding site of the $\beta$-cell $\mathrm{K}_{\mathrm{ATP}}$ channel. FEBS Lett 499, 154-160.

Mildner, A., Schmidt, H., Nitsche, M., Merkler, D., Hanisch, U.-K., Mack, M., Heikenwalder, M., Brück, W., Priller, J., and Prinz, M., 2007. Microglia in the adult brain arise from Ly-6ChiCCR2 ${ }^{+}$monocytes only under defined host conditions. Nat Neurosci 10, 1544-1553.

Milligan, E. D., and Watkins, L. R., 2009. Pathological and protective roles of glia in chronic pain, Nat Rev Neurosci, pp. 23-36.

Morrissey, A., Parachuru, L., Leung, M., Lopez, G., Nakamura, T. Y., Tong, X., Yoshida, H., Srivastiva, S., Chowdhury, P. D., Artman, M., and Coetzee, W. A., 2005. Expression 
of ATP-sensitive $\mathrm{K}+$ channel subunits during perinatal maturation in the mouse heart, Pediatric Research, pp. 185-192.

Napoli, I., and Neumann, H., 2009. Microglial clearance function in health and disease. Neuroscience 158, 1030-1038.

Neumann, J., Gunzer, M., Gutzeit, H. O., Ullrich, O., Reymann, K. G., and Dinkel, K., 2006. Microglia provide neuroprotection after ischemia. FASEB J 20, 714-716.

Neumann, J., Sauerzweig, S., Rönicke, R., Gunzer, F., Dinkel, K., Ullrich, O., Gunzer, M., and Reymann, K. G., 2008. Microglia cells protect neurons by direct engulfment of invading neutrophil granulocytes: a new mechanism of CNS immune privilege. J Neurosci 28, 5965-5975.

Nichols, C. G., 2006. $\mathrm{K}_{\text {ATP }}$ channels as molecular sensors of cellular metabolism. Nature 440, 470-476.

Nonoda, Y., Saito, Y., Itoh, M., Nakagawa, E., Sugai, K., Takahashi, A., Otsuki, T., Saito, Y., Arima, K., Mizuguchi, M., Goto, Y.-i., and Sasaki, M., 2009. Activation of microglia/macrophages expressing phosphorylated S6 ribosomal protein in a case of hemimegalencephaly with progressive calcification and atrophy. J Neurol Sci 287, 5259.

Ohno-Shosaku, T., and Yamamoto, C., 1992. Identification of an ATP-sensitive K+ channel in rat cultured cortical neurons. Pflugers Arch 422, 260-266.

Paxinos, G., and Watson, C., 1986. The rat brain in stereotaxic coordinates. Academic Press, Inc. U.S.A., San Diego.

Polazzi, E., and Monti, B., 2010. Microglia and neuroprotection: from in vitro studies to therapeutic applications. Prog Neurobiol 92, 293-315.

Proks, P., and Ashcroft, F. M., 2009. Modeling $\mathrm{K}_{\mathrm{ATP}}$ channel gating and its regulation. Prog Biophys Mol Biol 99, 7-19. 
Ramonet, D., Rodriguez, M. J., Pugliese, M., and Mahy, N., 2004. Putative glucosensing property in rat and human activated microglia. Neurobiol Dis 17, 1-9.

Rodriguez, M. J., Martínez-Sánchez, M., Bernal, F., and Mahy, N., 2004. Heterogeneity between hippocampal and septal astroglia as a contributing factor to differential in vivo AMPA excitotoxicity. J. Neurosci. Res. 77, 344-353.

Rodriguez, M. J., Prats, A., Malpesa, Y., Andres, N., Pugliese, M., Batlle, M., and Mahy, N., 2009. Pattern of injury with a graded excitotoxic insult and ensuing chronic medial septal damage in the rat brain. J Neurotrauma 26, 1823-1834.

Rodriguez, M. J., Robledo, P., Andrade, C., and Mahy, N., 2005. In vivo co-ordinated interactions between inhibitory systems to control glutamate-mediated hippocampal excitability. J Neurochem 95, 651-661.

Rodriguez, M. J., Ursu, G., Bernal, F., Cusí, V., and Mahy, N., 2001. Perinatal human hypoxia-ischemia vulnerability correlates with brain calcification. Neurobiol Dis 8, $59-68$.

Rolls, A., Shechter, R., London, A., Segev, Y., Jacob-Hirsch, J., Amariglio, N., Rechavi, G., and Schwartz, M., 2008. Two faces of chondroitin sulfate proteoglycan in spinal cord repair: a role in microglia/macrophage activation. PLoS Med 5, e171.

Saura, J., Tusell, J. M., and Serratosa, J., 2003. High-yield isolation of murine microglia by mild trypsinization. Glia 44, 183-189.

Schmued, L. C., Albertson, C., and Slikker, W., 1997. Fluoro-Jade: a novel fluorochrome for the sensitive and reliable histochemical localization of neuronal degeneration. Brain Res 751, 37-46.

Shaked, I., Tchoresh, D., Gersner, R., Meiri, G., Mordechai, S., Xiao, X., Hart, R. P., and Schwartz, M., 2005. Protective autoimmunity: interferon-gamma enables microglia to 
remove glutamate without evoking inflammatory mediators. J Neurochem 92, 9971009.

Simard, J. M., Chen, M., Tarasov, K. V., Bhatta, S., Ivanova, S., Melnitchenko, L., Tsymbalyuk, N., West, G. A., and Gerzanich, V., 2006. Newly expressed SUR1regulated $\mathrm{NC}_{\mathrm{Ca}-\mathrm{ATP}}$ channel mediates cerebral edema after ischemic stroke. Nat Med $12,433-440$.

Simard, J. M., Tsymbalyuk, N., Tsymbalyuk, O., Ivanova, S., Yurovsky, V., and Gerzanich, V., 2010. Glibenclamide Is Superior to Decompressive Craniectomy in a Rat Model of Malignant Stroke. Stroke 41, 531-537.

Simard, J. M., Yurovsky, V., Tsymbalyuk, N., Melnichenko, L., Ivanova, S., and Gerzanich, V., 2009. Protective effect of delayed treatment with low-dose glibenclamide in three models of ischemic stroke. Stroke 40, 604-609.

Stellwagen, D., and Malenka, R. C., 2006. Synaptic scaling mediated by glial TNF- $\alpha$. Nature 440, 1054-1059.

Streit, W. J., 2002. Microglia as neuroprotective, immunocompetent cells of the CNS. Glia 40, 133-139.

Streit, W. J., 2005. Microglia and neuroprotection: implications for Alzheimer's disease. Brain Res Brain Res Rev 48, 234-239.

Thored, P., Heldmann, U., Gomes-Leal, W., Gisler, R., Darsalia, V., Taneera, J., Nygren, J. M., Jacobsen, S.-E. W., Ekdahl, C. T., Kokaia, Z., and Lindvall, O., 2009. Long-term accumulation of microglia with proneurogenic phenotype concomitant with persistent neurogenesis in adult subventricular zone after stroke. Glia 57, 835-849.

Van Groen, T., Puurunen, K., Mäki, H.-M., Sivenius, J., and Jolkkonen, J., 2005. Transformation of diffuse $\beta$-amyloid precursor protein and $\beta$-amyloid deposits to 
plaques in the thalamus after transient occlusion of the middle cerebral artery in rats. Stroke 36, 1551-1556.

Veroni, C., Gabriele, L., Canini, I., Castiello, L., Coccia, E., Remoli, M. E., ColumbaCabezas, S., Aricò, E., Aloisi, F., and Agresti, C., 2010. Activation of TNF receptor 2 in microglia promotes induction of anti-inflammatory pathways. Mol Cell Neurosci 45, 234-244.

Wake, H., Moorhouse, A. J., Jinno, S., Kohsaka, S., and Nabekura, J., 2009. Resting microglia directly monitor the functional state of synapses in vivo and determine the fate of ischemic terminals. J Neurosci 29, 3974-3980.

Walberer, M., Nedelmann, M., Ritschel, N., Mueller, C., Tschernatsch, M., Stolz, E., Bachmann, G., Blaes, F., and Gerriets, T., 2010. Intravenous immunoglobulin reduces infarct volume but not edema formation in acute stroke. Neuroimmunomodulation 17, 97-102.

Weston, R. M., Jones, N. M., Jarrott, B., and Callaway, J. K., 2007. Inflammatory cell infiltration after endothelin-1-induced cerebral ischemia: histochemical and myeloperoxidase correlation with temporal changes in brain injury. $\mathrm{J}$ Cereb Blood Flow Metab 27, 100-114.

Wheeler, A., Wang, C., Yang, K., Fang, K., Davis, K., Styer, A. M., Mirshahi, U., Moreau, C., Revilloud, J., Vivaudou, M., Liu, S., Mirshahi, T., and Chan, K. W., 2008. Coassembly of different sulfonylurea receptor subtypes extends the phenotypic diversity of ATP-sensitive potassium (KATP) channels. Mol Pharmacol 74, 13331344.

Yamada, K., Ji, J. J., Yuan, H., Miki, T., Sato, S., Horimoto, N., Shimizu, T., Seino, S., and Inagaki, N., 2001. Protective Role of ATP-Sensitive Potassium Channels in HypoxiaInduced Generalized Seizure. Science 292, 1543-1546. 
Zausinger, S., Hungerhuber, E., Baethmann, A., Reulen, H., and Schmid-Elsaesser, R., 2000. Neurological impairment in rats after transient middle cerebral artery occlusion: a comparative study under various treatment paradigms. Brain Res 863, 94-105. 


\section{FIGURE LEGENDS}

Figure 1. BV2 microglial expression of K-ATP channel components. Murine BV2 cell culture was analyzed $48 \mathrm{~h}$ after activation with LPS+IFN $\gamma$ (see material and methods for details) (A, E, I) RT-PCR analyses of K-ATP channel subunits were performed with gene-specific primers (Table 1). PCR products for (A) SUR1, (E) Kir6.1 and (I) Kir6.2 and 18S as control of mRNA quantity in each reaction (arrows, 488bp) were separated by $1.5 \%$ agarose gel electrophoresis and stained with ethidium bromide. (Line 1) Each gel was loaded with standard size markers and (Line 2) cDNA amplified from: pancreas (SUR1 and Kir6.2) and lung (Kir6.1) as control; Line 3, non-activated BV2 cells; Line 4, BV2 cells activated with LPS+IFN $\gamma$; and Line 5, total RNA from HEK293 cells was used as negative controls. Amplified fragments had the sizes of 217bp for SUR1, 297pb for Kir6.1 and 312bp for Kir6.2 as predicted by the mRNA sequences amplicons. (B, F, J) Immunoblots of SUR1 (B), Kir6.1 (F) and Kir6.2 (J) expressed by control (Line a) and activated (Line b) BV2 cells. Homogenates were normalized for protein content quantified by Bradford's method and 15 $\mu \mathrm{g}$ of protein was applied in each gel lane. Bands appeared at the level of 190kDa for SUR1, 50kDa for Kir6.1 and 40kDa for Kir6.2. Actin-I was thereafter blotted as control of protein quantity in each gel (arrowhead, 43kDa). Immunocytochemistry with specific antibodies against (C, D) SUR1, (G, H) Kir6.1 and (K, L) Kir6.2 was performed in control and BV2 cells activated with LPS+IFN $\gamma$. Specific binding was detected with AlexaFluor 488conjugated secondary antibodies (green). Cell nuclei were counterstained with Hoescht33258 (blue). Note that activated BV2 cells are bigger and showed numerous processes. $(n=3$ different cultures). Scale Bar $20 \mu \mathrm{m}$.

Figure 2. BV2 cells are more reactive and phagocytic when are treated with Glibenclamide. (A-F) TNF $\alpha$ release, cell reactivity as morphology and phagocytic capacity of BV2 cells were 
assessed $48 \mathrm{~h}$ after activation with LPS+IFN $\gamma$ and pre-treated (left column) or post-treated (right column) with Gbc $10^{-5} \mathrm{nM}, 10^{-3} \mathrm{nM}$ or $1 \mathrm{nM}(\mathrm{n}=7)$. Bar graph show: (A-B) TNF $\alpha$ release quantified by ELISA and (C-D) reactive phenotype quantified as a perimeter/area ratio. (E-F) Graph shows the quantification of time course of the BV2-cell phagocytic capacity measured by fluosphere assay (\%). (G) Illustrative photomicrographs of BV2 cells during fluosphere assay after $5 \mathrm{~min}$ in presence of the beads (red). Cells were labeled with anti-tubulin (green) and DAPI (blue). Note that cells pre-treated with Gbc $10^{-5} \mathrm{nM}$ increased their phagocytic capacity and present more and longer processes, therefore increasing the ratio perimeter/area. All values are presented as mean \pm SEM ( $n=6$ different cultures). Statistics: In (A-D) $* P<0.05, * * P<0.01$ vs LPS+INFg; ${ }^{\&} P<0.05$ vs other Gbc doses; ${ }^{\$} P<0.05$ vs Control. In (E-F) $* P<0.05$ vs LPS+INFg; ${ }^{\#} P<0.05$ different from all the other groups. Scale bar $25 \mu \mathrm{m}$.

Figure 3. Glibenclamide reaches the ischemic brain and improves the neurological outcome of tMCAo animals. (A) Specific $\left[{ }^{3} \mathrm{H}\right] \mathrm{Gbc}$ binding in control and ischemic brain. (B) Timing of the 7-point Neuroscore values presented by tMCAo animals in a dose response study of three Gbc doses $(0.06 \mu \mathrm{g}, 0.6 \mu \mathrm{g}$ and $6 \mu \mathrm{g})$ and vehicle; arrows indicate the time of Gbc i.v. administration, see material and methods for details. (C) Representative T2-MRI image $72 \mathrm{~h}$ after tMCAo in vehicle and $0.06 \mu \mathrm{g}$ Gbc-treated animals. (D) Bar graph of total lesion volumes calculated from MRI data of all animals included in the dose response study. Results are represented separately as Mean $( \pm \mathrm{SEM})$ for all the groups $(\mathrm{n}=15$ rats/group). Statistics: $* * P<0.01$ different from control in (A) and compared with the $24 \mathrm{~h}$ time point in (B) (LSD post-hoc test). 
Figure 4. Glibenclamide causes neuroprotection in ischemic brains. Representative NeuN immunostaining: (A) control brain and (B) tMCAo brain, both on the ischemic core level (Bregma from $-0,8$ to -1.8$)$. $\left(\mathbf{B}_{1}, \mathbf{B}_{2}\right)$ Analysis at higher magnification of infarcted brain evidenced 3 different regions: healthy and organized tissue (1), peri-infarcted region with a decreased number of neurons and tissue disorganization (2), and a necrotic zone with few scattered NeuN-positive cells and more tissue disorganization (3). The effects of three Gbc doses $(0.06 \mu \mathrm{g}, 0.6 \mu \mathrm{g}$ and $6 \mu \mathrm{g})$ were compared to vehicle administration by a histological approach. Quantification of the lesioned, necrotic and peri-infarcted volumes and neuronal counts was made at the ischemic core by stereology. Photomicrographs of the Ventral Pallidum nuclei $(\mathbf{C})$, which corresponds with the boundary between the necrotic core and peri-infarct area for a vehicle-treated $\left(\mathbf{D}_{1}\right)$ or for a Gbc $0.6 \mu \mathrm{g}$ treated animals $\left(\mathbf{D}_{2}\right)$. Note that in Gbc $0.6 \mu \mathrm{g}$ treated animals $\left(\mathbf{D}_{2}\right)$ the necrotic area is smaller and more NeuN-positive cells are observed in the boundary. (E) Photomicrograph of degenerating neurons stained with FluoroJade B (FJB) in the peri-infarcted cortex of tMCAo animals. Bar graphs of the (F) total lesioned, (G) total necrotic and $(\mathbf{H})$ subcortical peri-infarcted volumes are shown together with stereological counting of NeuN-positive cells into the (I) subcortical lesion, (J) total necrotic and (K) subcortical peri-infarcted zones. Note that Gbc increase peri-infarcted volume and neuronal preservation into the subcortical region. This resulted in a 30-40\% preservation of neurons in the total lesioned hemisphere, since no Gbc cortical effects were observed (data not shown). Values are presented as mean $( \pm S E M)$ for all the groups $(n=15$ rats/group). Statistics: ${ }^{\# \#} P<0.01$ different from vehicle; ${ }^{++} P<0.01$ different from Gbc $0.06 \mu \mathrm{g}$; ${ }^{* *} \mathrm{p}<0.01$ different from vehicle and $0.06 \mu \mathrm{g} ;{ }^{\infty}{ }^{\infty} P<0.01$ different from all. Scale Bar, $50 \mu \mathrm{m}$.

Figure 5. Ischemic brain showed calcification. (A) Calcium deposition in the subcortical zone stained with $2 \%$ Alizarin red S counterstained with $0.5 \%$ Fast Green FCF. The effects in 
calcification of three Gbc doses $(0.06 \mu \mathrm{g}, 0.6 \mu \mathrm{g}$ and $6 \mu \mathrm{g})$ compared with vehicle were studied in cortical and subcortical brain regions. $\left(\mathbf{A}_{\mathbf{1}}\right)$ Images from a vehicle- and Gbc-treated animals. $\left(\mathbf{A}_{2}\right)$ High magnification photomicrograph of a single calcium deposit. Histograms show (B) the diameter size average of deposits and (C) the total number of calcium deposits per section $(\mathrm{n}=15$ rats/group). All values are presented as mean \pm SEM. $* P<0.05$ and $* * *$ $P<0.001$ different from vehicle; ${ }^{\#} P<0.05$ and ${ }^{\# \# \#} P<0.001$ different from Gbc $0,06 \mu$ g; Scale Bar: $\left(\mathrm{A}_{1}\right) 150 \mu \mathrm{m} ;\left(\mathrm{A}_{2}\right) 10 \mu \mathrm{m}$.

Figure 6. Analysis of astroglial reactivity to tMCAo. (A, B) We visualized astrocyte distribution by GFAP imunohistochemistry in the entire tMCAo hemisphere and an area lacking specific GFAP immunostaining was found close to the astroglial scar (Asterisk), coincident with the necrotic core. These areas were measured individually in the cortical and subcortical regions and pooled as total area, which valued was not modified by Gbc treatment (data not shown). Non-reactive astrocytes were found in distal regions from the lesion. (C) Bar graph shows the astrocyte cell density quantified individually in each brain region of control $(n=4)$, vehicle $(n=15)$ and Gbc-treated brains $(0.06 \mu \mathrm{g}, 0.6 \mu \mathrm{g}$ and $6 \mu \mathrm{g} ; \mathrm{n}=15$ rats/group). (D) Illustrative $\mathrm{S} 100 \beta$ immunostaining images of the corpus callossum from the injured hemispheres (\&; labels for Striatum). (E) Photomicrographs from: control brain showed organized tissue and small S100 $\beta$ cells with processes following the axons; tMCAo lesion caused tissue disorganization and increase $\mathrm{S} 100 \beta$ immunoreactivity and in the Gbctreated tMCAo groups $S 100 \beta$ positive cells presented major body volumes and higher number of processes. Values are presented as mean \pm SEM. Scale Bar, $300 \mu \mathrm{m}$ in (A), $150 \mu \mathrm{m}$ in (D) and $20 \mu \mathrm{m}$ in $(\mathrm{B}, \mathrm{E})$. 
Figure 7. tMCAo caused microglia reaction of variable morphology depending on its proximity to the infarct core. (A) Histogram shows microglial density determined individually in each brain region of control, vehicle and Gbc-treated brains $(0.06 \mu \mathrm{g}, 0.6 \mu \mathrm{g}$ and $6 \mu \mathrm{g})$. Ischemia triggers an increase of microglial density compared with control brain. (B) Confocal microscopy photomicrograph of CD3-immunostained T-lymphocyte (CD3) infiltration in the infarct core, where IB4 positive microglia/macrophages (IB4) were reactive. Note that merged image show both type of cells with tight contacts, suggesting a neuro-immune crosstalk as a response to the lesion. Low magnification photomicrographs from $(\mathbf{C})$ cortex and (D) caudate putamen, which shows continuity of the microgliosis reaction to the lesion. (E-H) Higher magnification photomicrographs showed variable microglial phenotype. (E) Resting microglial morphology was viewed in healthy tissue. (F) Reactive microglial cells were present in peri-infarcted areas and were more ramified than quiescent ones, with numerous processes. (G) Mixed morphology, some reactive and some amoeboid cells were detected in the border between peri-infarcted and necrotic areas. (H) Fully amoeboid shaped morphology cells were viewed in the necrotic core. Values are presented as mean \pm SEM ( $n=$ 15 rats/group). Statistics: $* * P<0.01$ and $* * * P<0.001$ different from control. Scale Bar, 300 $\mu \mathrm{m}$ in (D) and $20 \mu \mathrm{m}$ in $(\mathrm{B}, \mathrm{H})$.

Figure 8. Expression of $K_{A T P}$ channel components SUR1, SUR2B and Kir6.2 in activated CD11b-positive cells into the core of the lesion (Bregma -0,8). (A-D) Confocal photomicrographs of SUR1 in resting microglia from control animals denote no colocalization. Reactive CD11b-positive cells expressed (E-H) SUR1, (I-L) SUR2B and (MP) Kir6.2 channel subunits in the lesion core. (D, H, L, P) show scatter plots from its correspondent merged images from each row of the $\mathrm{K}_{\mathrm{ATP}}$ channel components in reactive CD11b-positive cells. From left to right in the $\mathrm{X}$-axis corresponds with the increase of the 
green channel intensity, whereas, from down to up in the $\mathrm{Y}$-axis corresponds with the increase of the red channel. Yellow dots denote colocalization for both channels, in which CD11bpostive cells expressed SUR1 (D, H), SUR2B (L) and Kir6.2 (P). Scale Bar, $20 \mu \mathrm{m}$.

Supplementary Figure 1. Quantification of the lesion areas in the tMCAO hemisphere. Hematoxolin-Eosin stainings images of the ypsilateral hemisphere from (A) control, (B) vehicle and (C) glibenclamide 0,6 $\mu \mathrm{g}$ treated brain. Photomicrograph from the vehicle-treated animal, which show the boundary of the lesions in the cortex $\left(\mathbf{B}_{1}\right)$ or the striatum $\left(\mathbf{B}_{2}\right)$. Graphical respresentation of the cortical (D), subcortical (E) and the total lesioned area (F) along the bregma axis. Note that although not statistical differences were found, treated groups had lower values for lesioned areas in all bregma levels studied. Scale bar $200 \mu \mathrm{m}$. 
Table 1. Primer sequences used for RT-PCR.

\begin{tabular}{llll}
\hline Species & Size $(\mathrm{bp})$ & Primer & Sequence \\
\hline \multirow{2}{*}{ Kir6.1 } & \multirow{2}{*}{297} & F & 5'-ACCAGAATTCTCTGCGGAAG-3' \\
& & R & 5'-GCCCTGAACTGGTGATGAGT-3' \\
\hline \multirow{2}{*}{ Kir6.2 } & \multirow{2}{*}{312} & F & 5'-TTGGAAGGCGTGGTAGAAAC-3' \\
& & R & 5'-GGACAAGGAATCTGGAGAGAT-3' \\
\hline \multirow{2}{*}{ SUR1 } & \multirow{2}{*}{217} & F & 5'-GCCTTCGTGAGAAAGACCAG-3' \\
& & R & 5'-GAAGCTTCTCCGGTTTGTCA-3' \\
\hline \multirow{2}{*}{ SUR2A/B } & \multirow{2}{*}{ SUR2A: 397 } & F & 5'-ATCATGGATGAAGCCACTGC-3' \\
& SUR2B: 221 & R & 5'-AACGAGGCAAACACTCCATC-3' \\
\hline \multirow{2}{*}{ 18S } & 488 & F & 5'-TCAAGAACGAAAGTCGGAGG-3' \\
& & R & 5'-GGACATCTAAGGGCATCACA-3' \\
\hline
\end{tabular}

$\mathrm{F}$ and $\mathrm{R}$ are referred to forward and reverse primers respectively. 


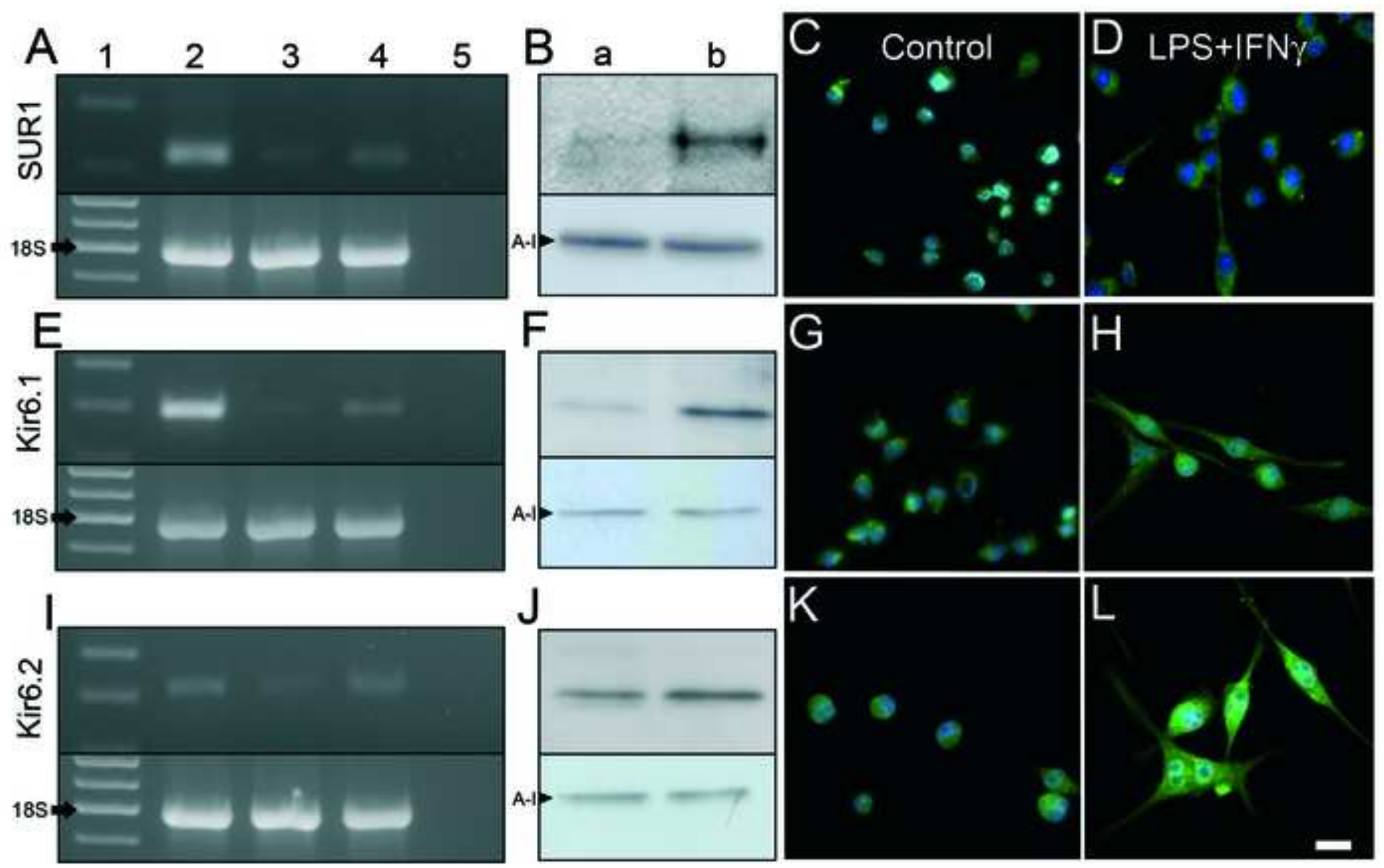




\section{Figure 2}

Click here to download high resolution image

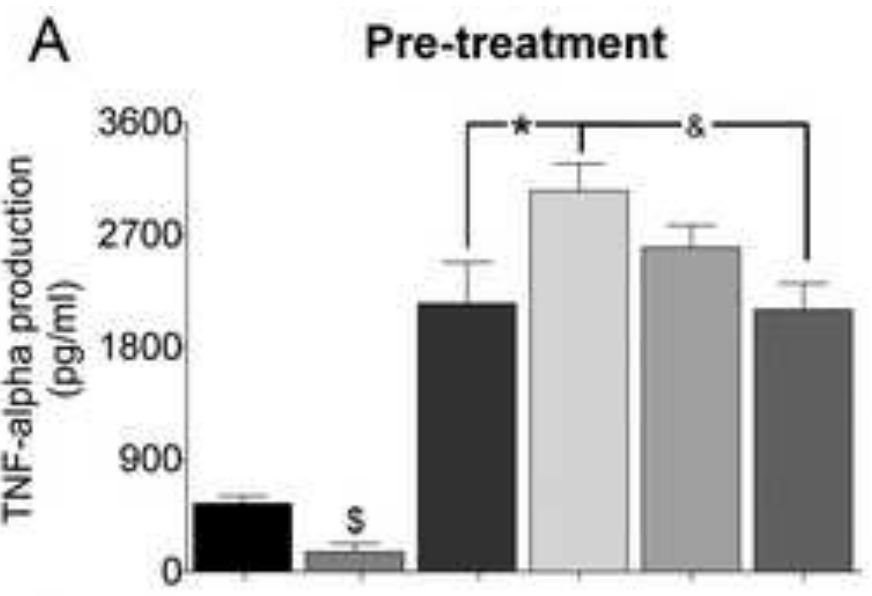

B

\section{Post-treatment}
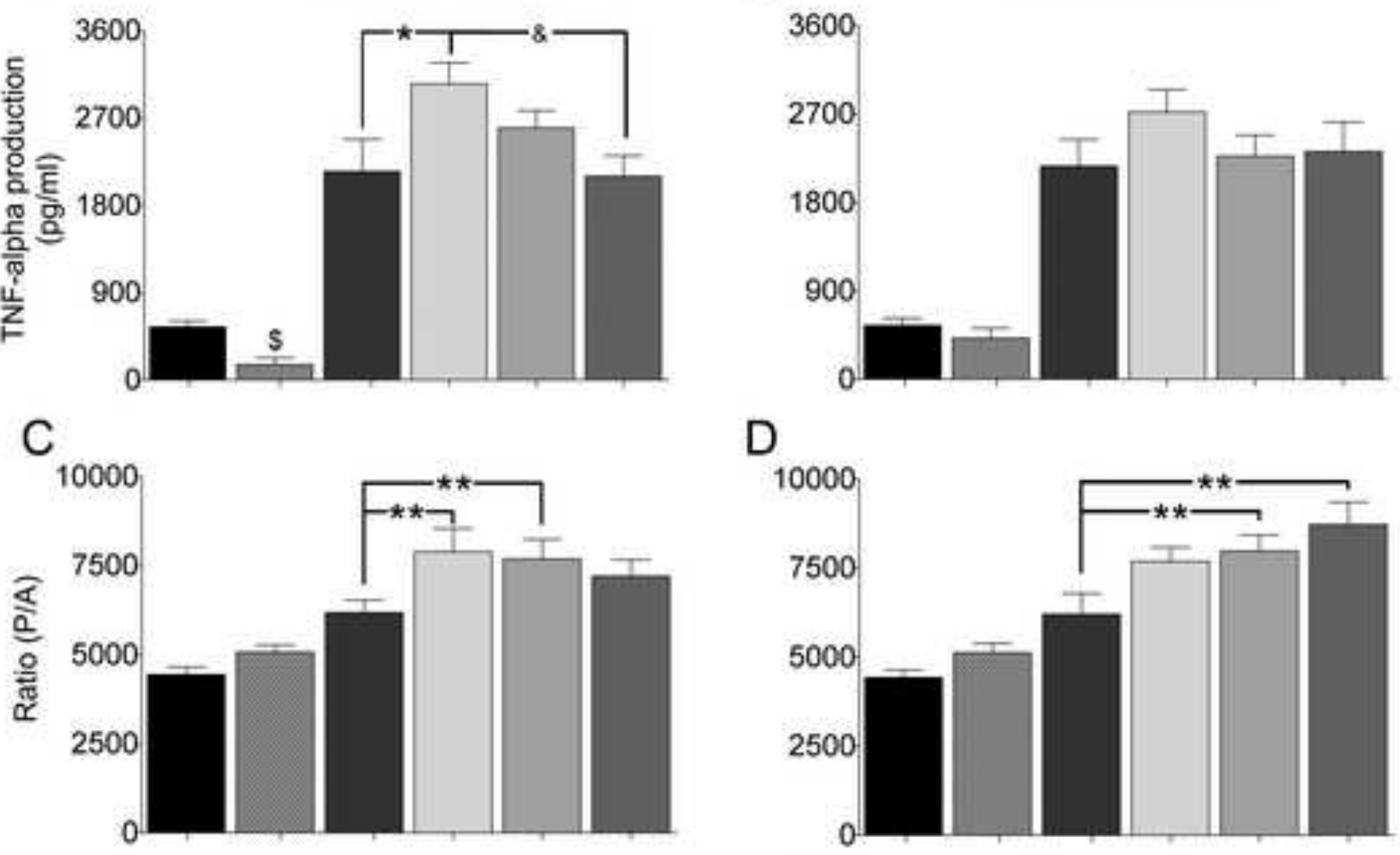

D
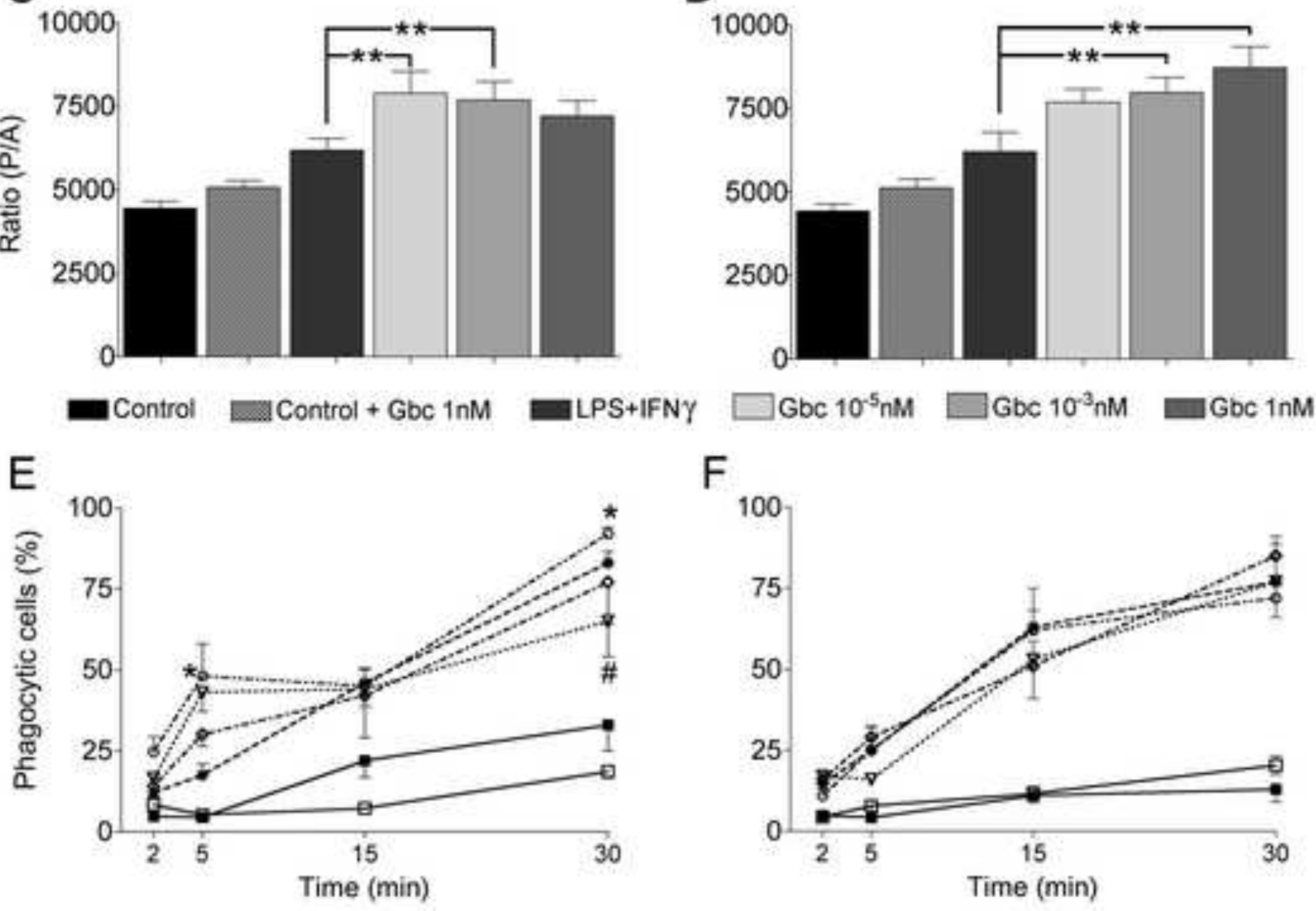

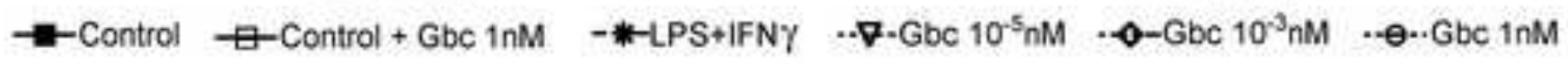
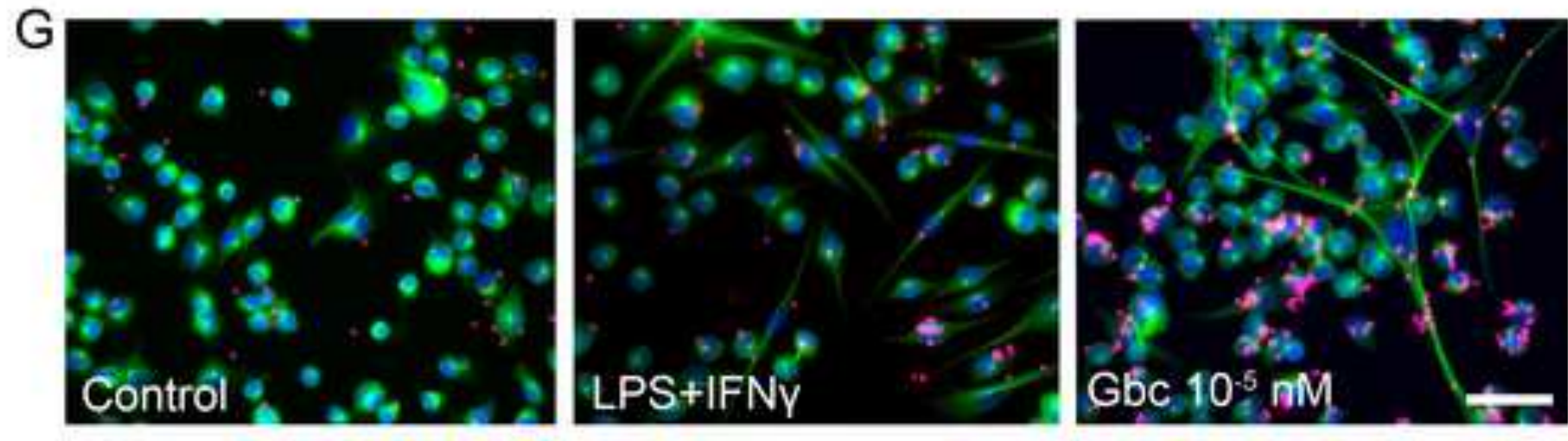

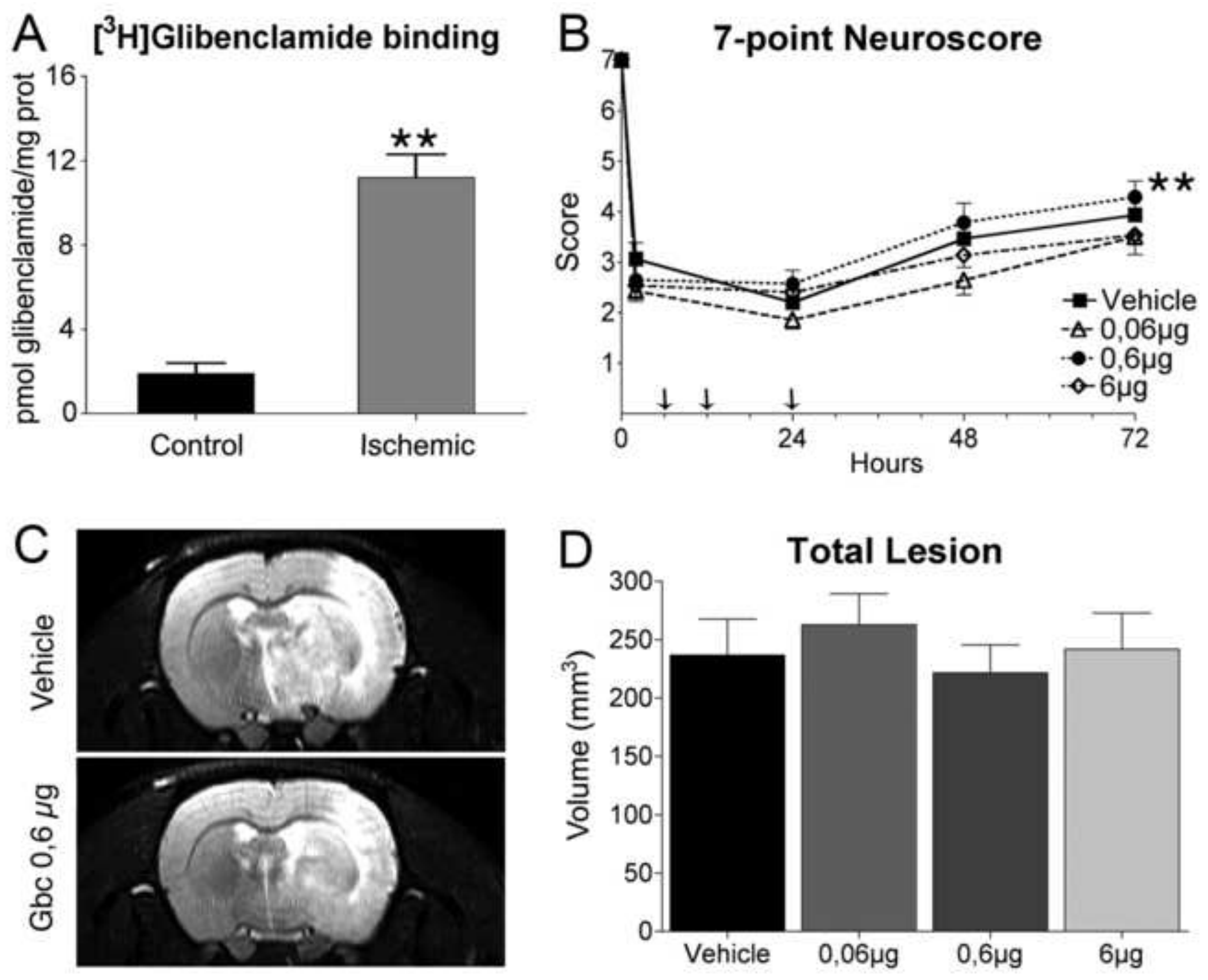


\section{Figure 4}

Click here to download high resolution image

A
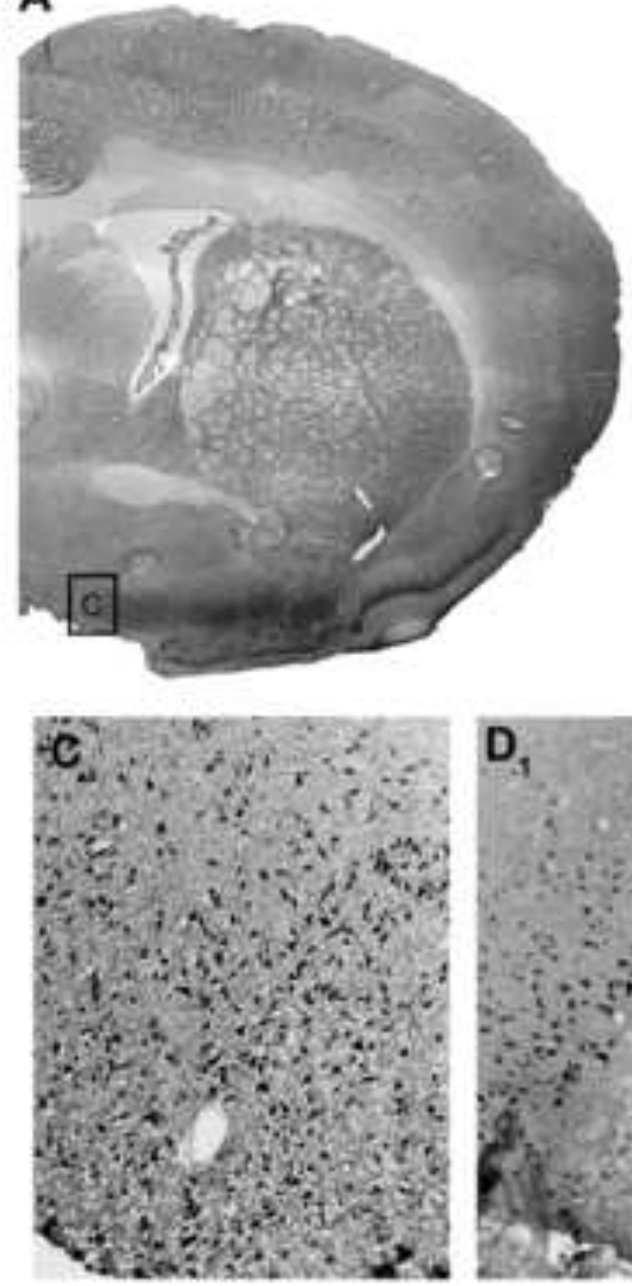

D.

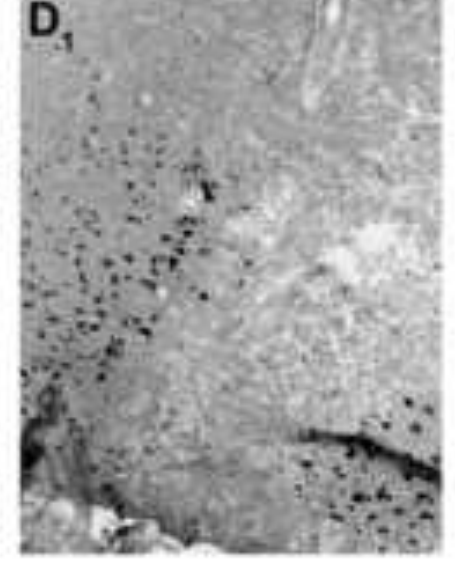

$\mathrm{F}$

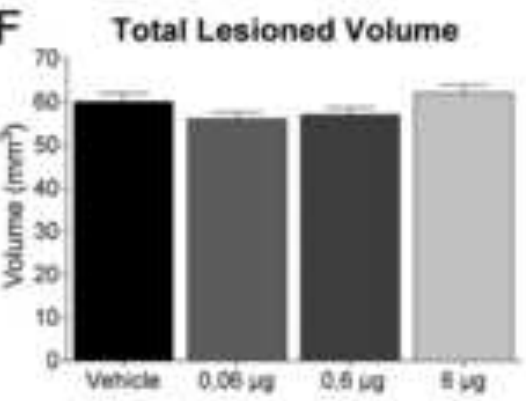

I Subcortical Lesioned Volume

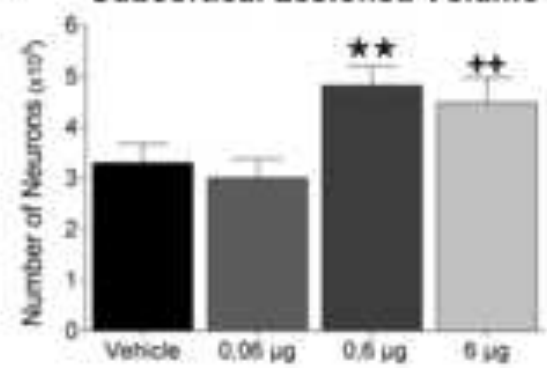

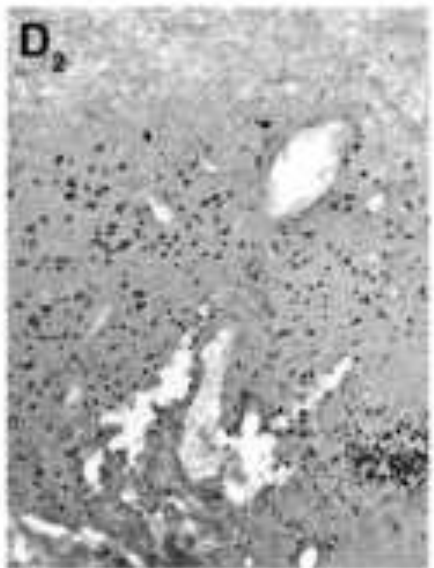

B

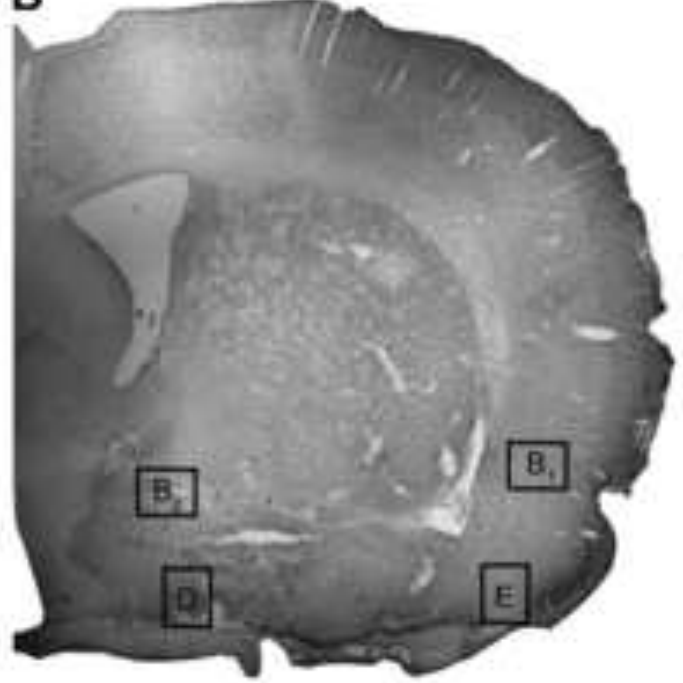

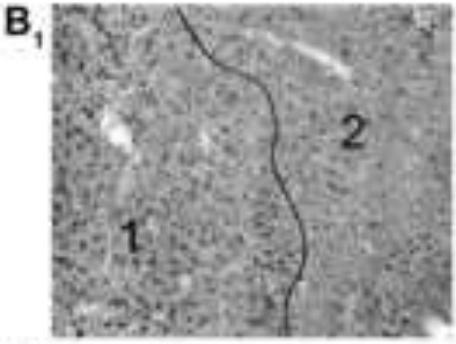

$\mathrm{B}_{2}$

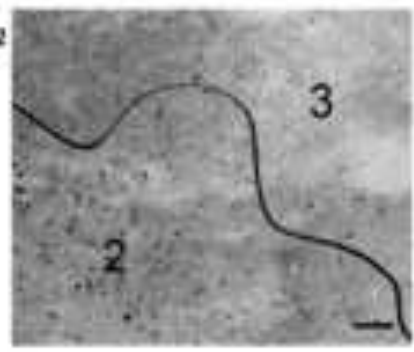

$\mathrm{E}$

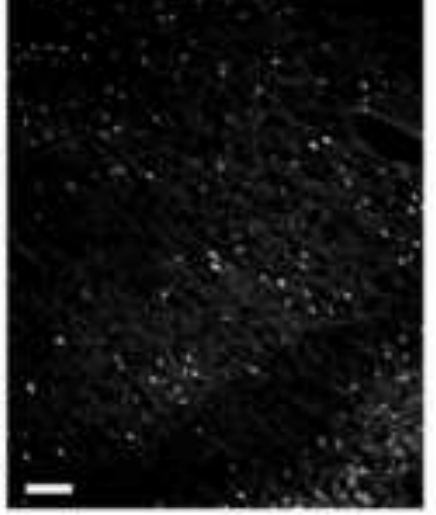

H Subcortical peri-infarct Volume

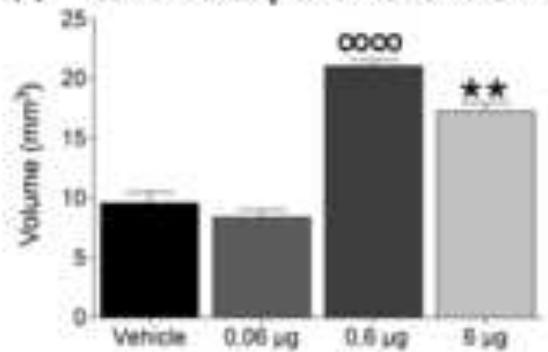

K subcortical peri-infarct Volume

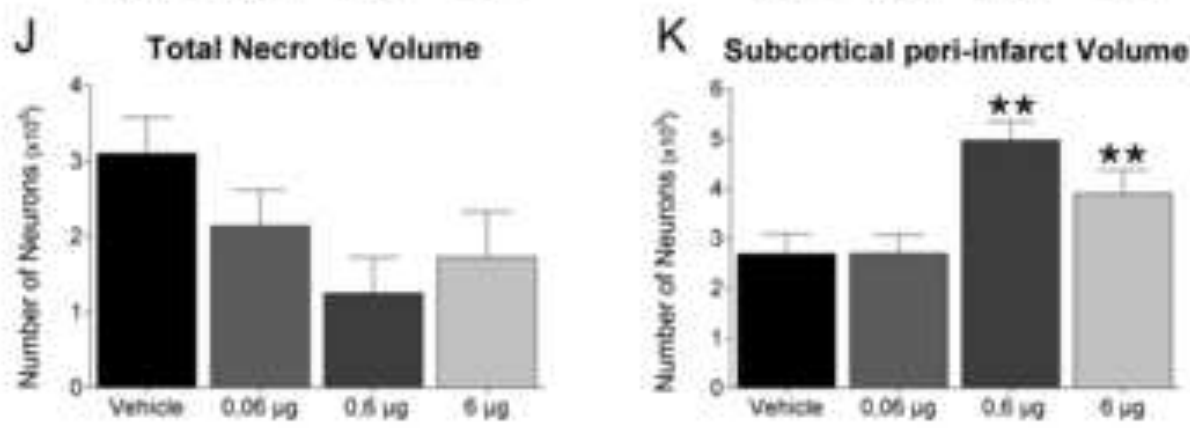

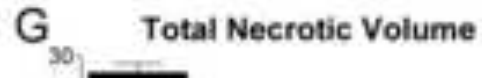
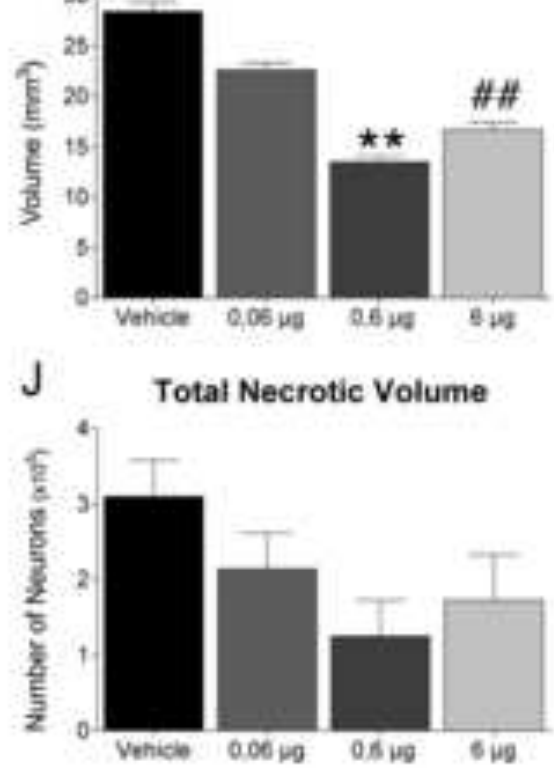

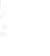



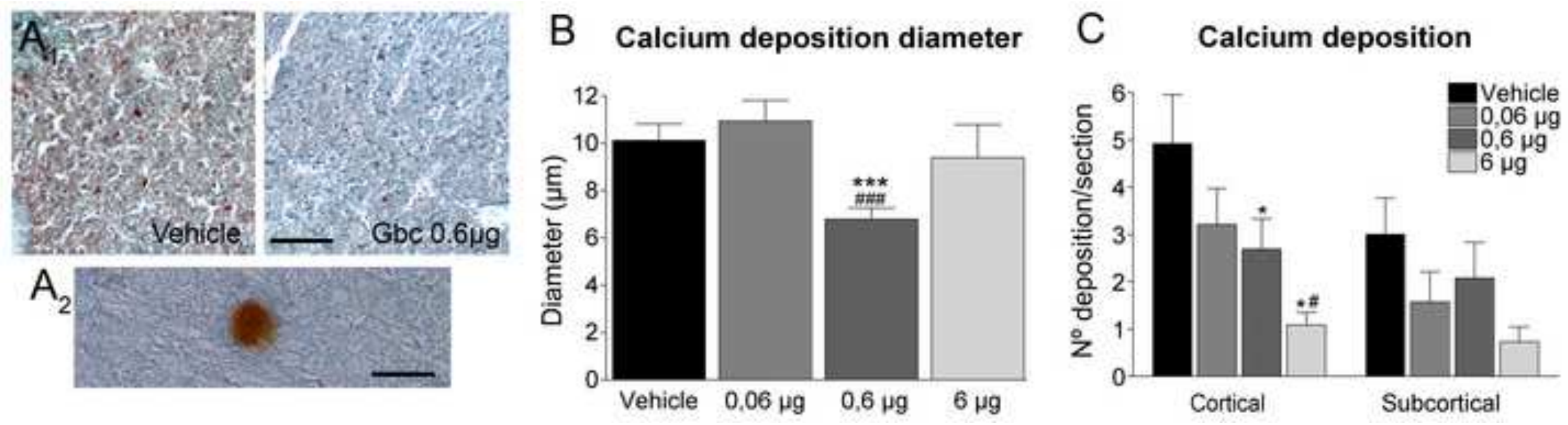
Figure 6

Click here to download high resolution image

A
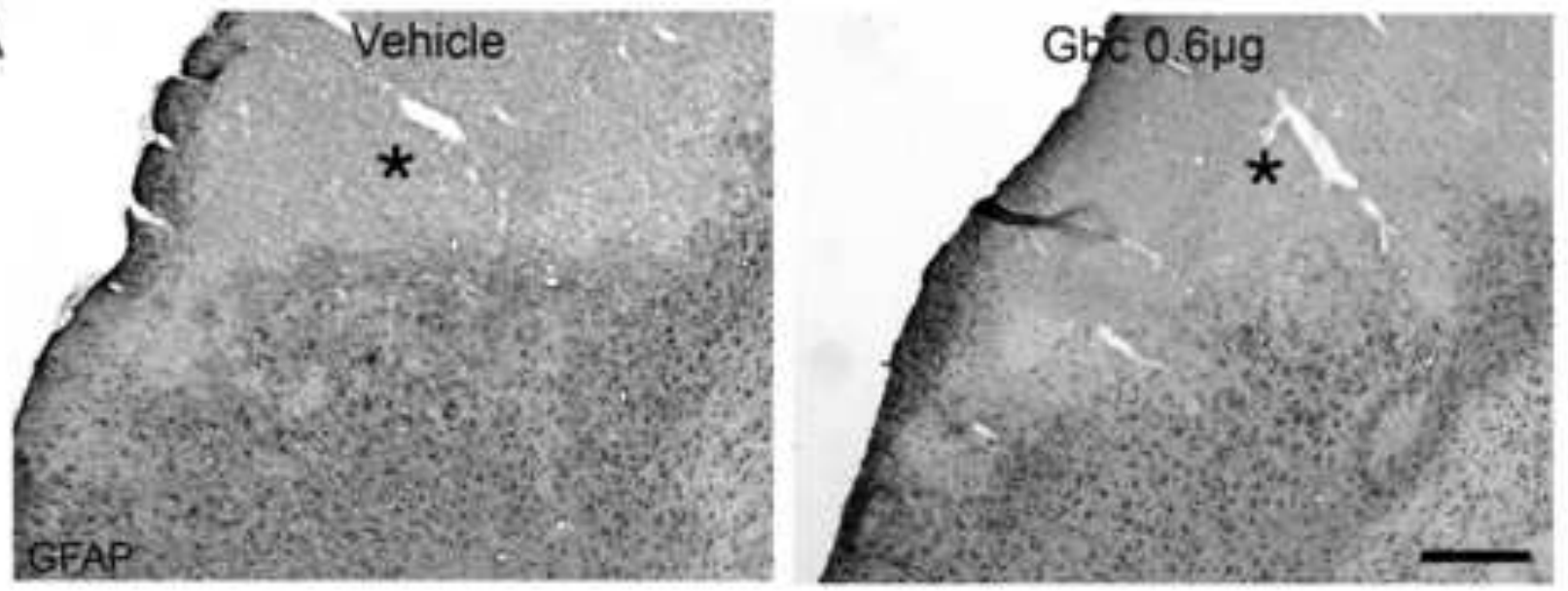

B
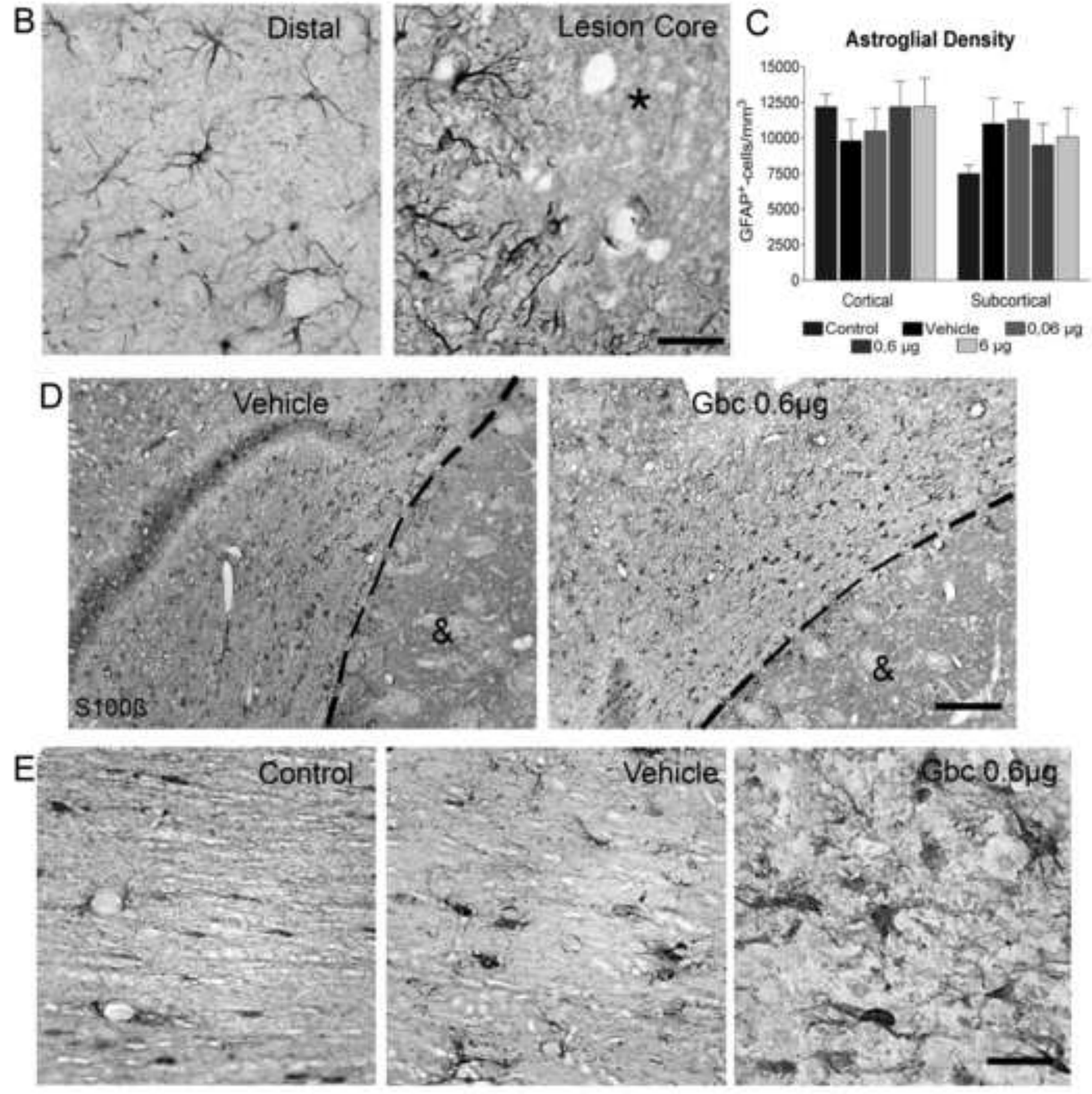

E. 


\section{Figure 7}

Click here to download high resolution image
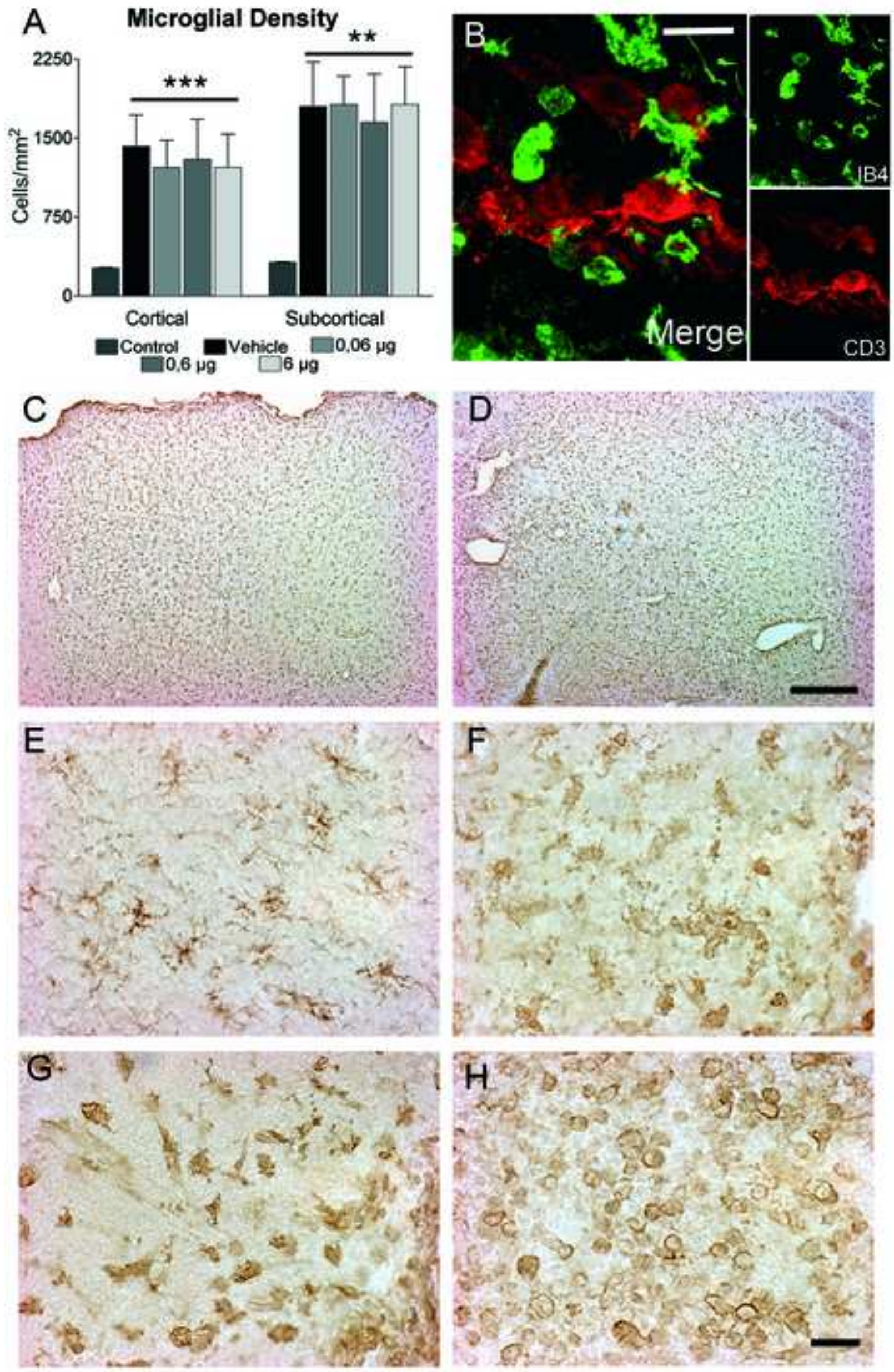

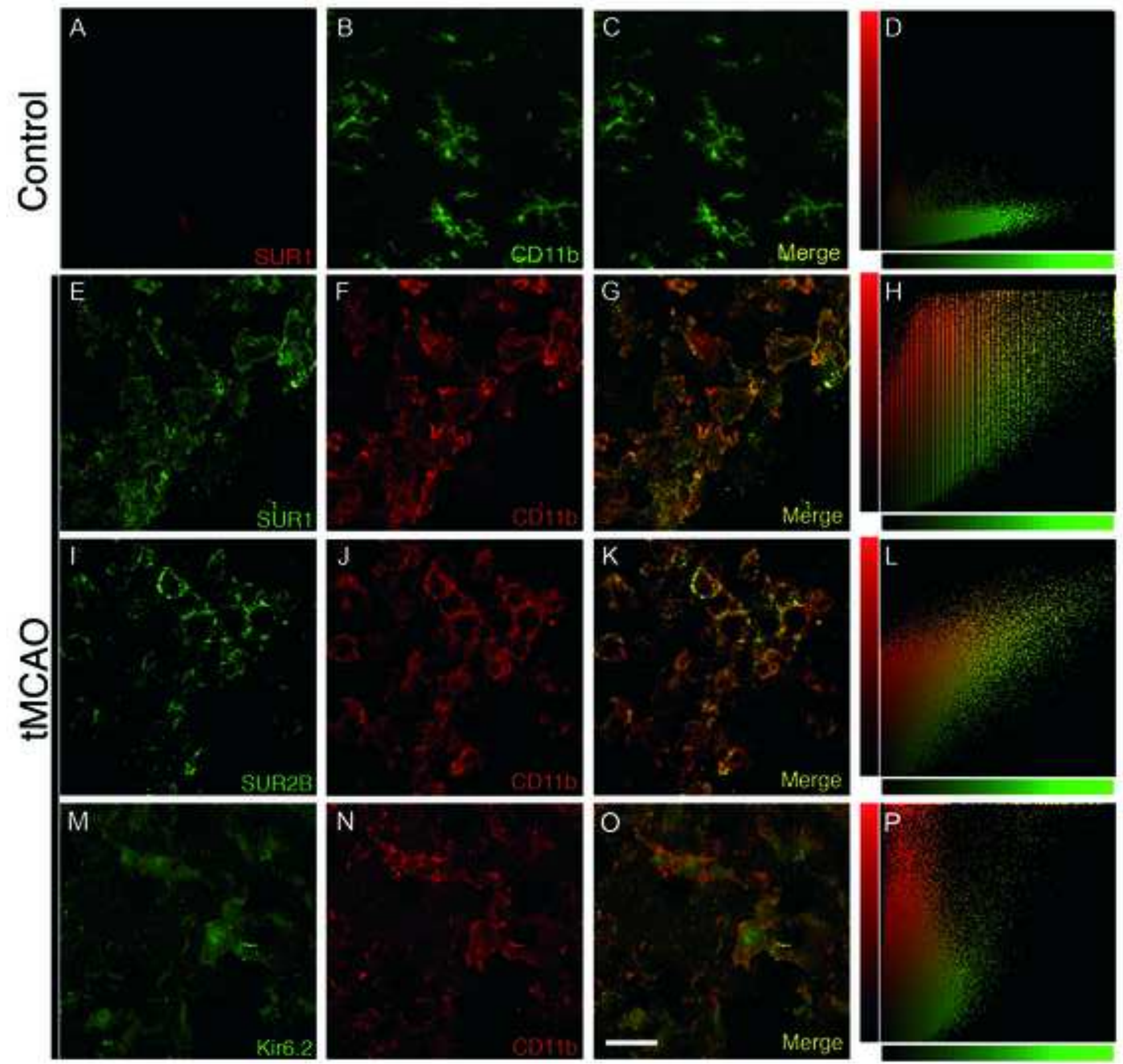
Supplementary Figure 1
Click here to download Supplementary Material: Figura_Suppl_Data1_1.tif

(a)

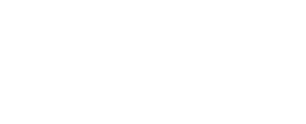

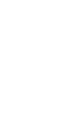

(1)

(1)

西

西

西

西

西

西

西

西

(n)

(n)

(n)

(n)

西

西

西

西

西

西

西

西

西

(1)

西

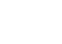

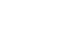

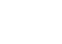

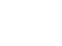

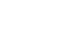

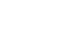

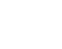

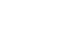

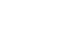

